\title{
Kainate Receptor Auxiliary Subunit NETO2-Related Cued Fear Conditioning Impairments Associate with Defects in Amygdala Development and Excitability
}

\author{
Marie Mennesson, ${ }^{1,2,3,4^{*}}$ Ester Orav, ${ }^{2,3^{*}}$ Adrien Gigliotta, ${ }^{1,2,3,4}$ Natalia Kulesskaya, ${ }^{2}$ Suvi Saarnio, ${ }^{2}$ \\ Anna Kirjavainen, ${ }^{2}$ Sebnem Kesaf, ${ }^{2,3}$ Frederike Winkel, ${ }^{3}$ Maria Llach Pou, ${ }^{3}$ Juzoh Umemori, ${ }^{3}$ \\ - Vootele Voikar, ${ }^{3}$ Victoria Risbrough, ${ }^{5,6}$ Juha Partanen, ${ }^{2}$ Eero Castrén, ${ }^{3}$ (D) Sari E. Lauri, ${ }^{2,3}$ and \\ Oliris Hovatta ${ }^{1,2,3,4}$
}

\section{https://doi.org/10.1523/ENEURO.0541-19.2020}

${ }^{1}$ Department of Psychology and Logopedics, Medicum, University of Helsinki, Helsinki 00290, Finland, ${ }^{2}$ Molecular and Integrative Biosciences Research Program, University of Helsinki, Helsinki 00790, Finland, ${ }^{3}$ Neuroscience Center, Helsinki Institute of Life Science HiLIFE, University of Helsinki, Helsinki 00290, Finland, ${ }^{4}$ SleepWell Research Program, Faculty of Medicine, University of Helsinki, Helsinki 00290, Finland, ${ }^{5}$ Center of Excellence for Stress and Mental Health, Veterans Affairs, La Jolla, CA 92093, and ${ }^{6}$ Department of Psychiatry, University of California, La Jolla, CA 92093

\section{Visual Abstract}

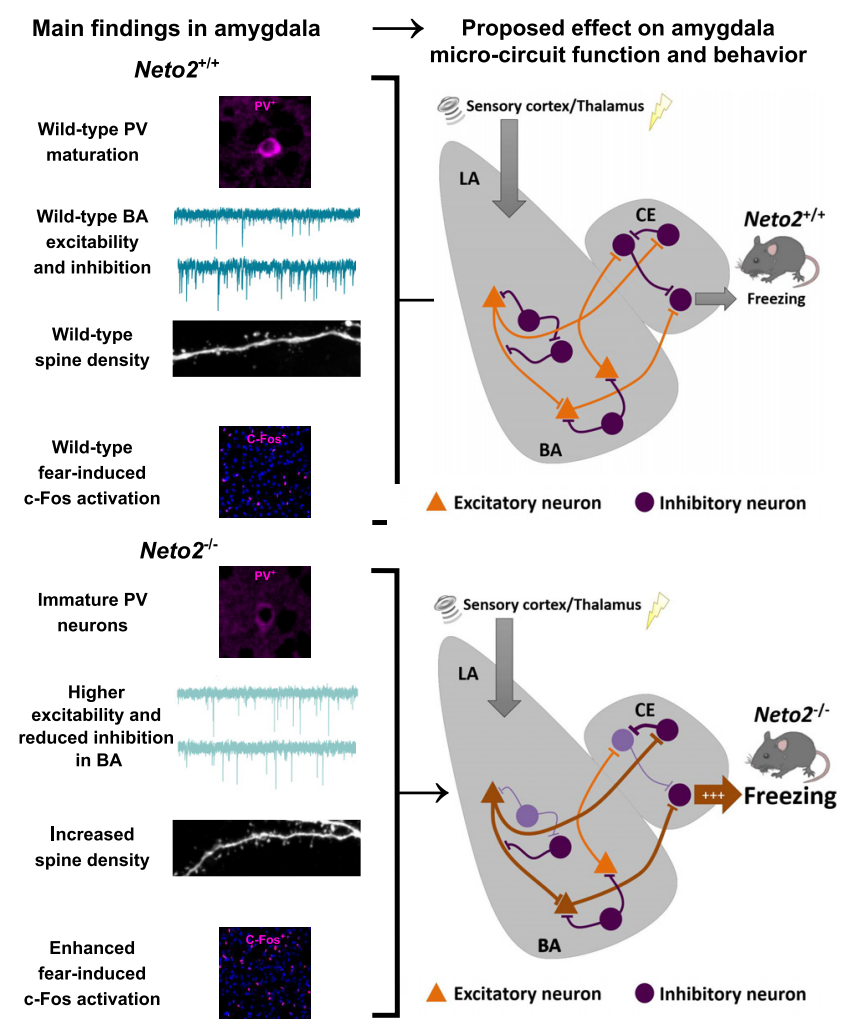

NETO2 is an auxiliary subunit for kainate-type glutamate receptors that mediate normal cued fear expression and extinction. Since the amygdala is critical for these functions, we asked whether Neto2 ${ }^{-1-}$ mice have compromised amygdala function. We measured the abundance of molecular markers of neuronal maturation and plasticity, parvalbumin-positive $\left(\mathrm{PV}^{+}\right)$, perineuronal net-positive $\left(\mathrm{PNN}^{+}\right)$, and double positive $\left(\mathrm{PV}^{+} \mathrm{PNN}^{+}\right)$cells 


\section{Significance Statement}

NETO2 is required for normal fear expression and extinction in cued fear conditioning, but the underlying mechanisms remain unknown. Since amygdala is a central brain region regulating fear responses, we investigated its maturation and function in $\mathrm{Neto}^{-/-}$and $\mathrm{Neto}^{+/+}$mice. Neto2 ${ }^{-1-}$ mice had stronger fear expression and slower extinction than $\mathrm{Neto}^{+/+}$mice, associated with amygdala hyperexcitability. We propose that defects in the Neto2 $2^{-1-}$ mice involving amygdala PV-interneuron network configuration and amygdala excitation and inhibition imbalance through multiple mechanisms contribute to the fear phenotype of these mice. These findings could inform novel targets for fear-related disorders, such as phobias and posttraumatic stress disorder (PTSD).

in the Neto2 ${ }^{-1-}$ amygdala. We found that $\mathrm{Neto}^{-1-}$ adult, but not postnatal day $(\mathrm{P}) 23$, mice had $7.5 \%$ reduction in the fraction of $\mathrm{PV}^{+} \mathrm{PNN}^{+}$cells within the total $\mathrm{PNN}^{+}$population, and $23.1 \%$ reduction in $\mathrm{PV}$ staining intensity compared with $\mathrm{Neto}^{+/+}$mice, suggesting that PV interneurons in the adult $\mathrm{Neto}^{-/-}$amygdala remain in an immature state. An immature PV inhibitory network would be predicted to lead to stronger amygdalar excitation. In the amygdala of adult $\mathrm{Neto}^{-1-}$ mice, we identified increased glutamatergic and reduced GABAergic transmission using whole-cell patch-clamp recordings. This was accompanied by increased spine density of thin dendrites in the basal amygdala (BA) compared with $\mathrm{Neto} 2^{+/+}$mice, indicating stronger glutamatergic synapses. Moreover, after fear acquisition Neto ${ }^{-/-}$mice had a higher number of c-Fos-positive cells than $\mathrm{Neto}^{+/+}$mice in the lateral amygdala (LA), BA, and central amygdala (CE). Altogether, our findings indicate that Neto2 is involved in the maturation of the amygdala PV interneuron network. Our data suggest that this defect, together with other processes influencing amygdala principal neurons, contribute to increased amygdalar excitability, higher fear expression, and delayed extinction in cued fear conditioning, phenotypes that are common in fear-related disorders, including the posttraumatic stress disorder (PTSD).

Key words: amygdala; excitability; fear conditioning; immunohistochemistry; interneuron; knock-out mouse

\section{Introduction}

NETO2 is an auxiliary subunit of kainate-type ionotropic glutamate receptors (KARs), and it thereby modulates biophysical properties and agonist affinity of KARs (Zhang et al., 2009; Wyeth et al., 2017). In addition, NETO2 also interacts with $\mathrm{K}-\mathrm{Cl}$ co-transporter 2 (KCC2), and together

Received December 22, 2019; accepted July 24, 2020; First published August $11,2020$.

The authors declare no competing financial interests.

Author contributions: M.M., S.E.L., and I.H. designed research; M.M., E.O., A.G., N.K., and S.S. performed research; A.K., S.K., F.W., M.L.P., J.U., V.V., V.R., J.P., and E.C. contributed unpublished reagents/analytic tools; M.M., E.O., and A.G. analyzed data; M.M., E.O., A.G., S.E.L., and I.H. wrote the paper.

This work was supported by the Jane and Aatos Erkko Foundation (I.H., S.E.L., and V.V.), the Sigrid Jusélius Foundation (I.H. and E.C.), the Academy of Finland (E.C.), the Oskar Öflund Foundation (M.M.), the Finnish Cultural Foundation (M.M.), the Jalmari and Rauha Ahokas Foundation (M.M.), and the A*MIDEX Grant ANR-11-IDEX-0001-02 funded by the French Government «Investissements d'Avenir» program (to A.G.).

${ }^{*}$ M.M. and E.O. contributed equally to this work.

Acknowledgements: We thank Roderick R. McInnes for the Neto2 mouse line, Pierre Ameslon, Falk Gogolla, Zuzanna Misiewicz, and Mikaela Laine for technical help and Pirta Hotulainen, Petri Hyytiä, Hovatta lab, Lauri lab, and Partanen lab members for helpful discussions. We also thank the Mouse Behavioral Phenotype Facility (MBPF), supported by Biocenter Finland and Helsinki Institute of Life Science, for the use of their facilities.

Correspondence should be addressed to liris Hovatta at iiris.hovatta@ helsinki.fi or Sari E. Lauri at sari.lauri@helsinki.fi.

https://doi.org/10.1523/ENEURO.0541-19.2020

Copyright $\odot 2020$ Mennesson et al.

This is an open-access article distributed under the terms of the Creative Commons Attribution 4.0 International license, which permits unrestricted use, distribution and reproduction in any medium provided that the original work is properly attributed. with KARs influence its expression in the hippocampal neurons (Ivakine et al., 2013; Pressey et al., 2017). Both male and female Neto $2^{-1-}$ mice have normal innate anxiety-like behavior, but greater fear expression and delayed extinction in cued fear conditioning compared with Neto $2^{+/+}$mice, resembling fear phenotypes associated with posttraumatic stress disorder (PTSD; Mennesson et al., 2019). Furthermore, the synaptic KAR abundance of Neto $2^{-/-}$mice is significantly reduced in fear-related brain regions, including the amygdala, medial prefrontal cortex (mPFC), and ventral hippocampus (vHpc; Mennesson et al., 2019).

The amygdala is a group of heterogeneous nuclei central to fear learning, memory consolidation, and fear expression. Its main subnuclei are the lateral (LA), basal (BA), and central (CE) amygdala (Herry and Johansen, 2014; Tovote et al., 2015). Fear-inducing stimuli are processed in the LA, where both cortical and thalamic inputs project onto glutamatergic principal neurons (Ehrlich et al., 2009; Herry and Johansen, 2014), mediating neural plasticity and fear learning (Johansen et al., 2010, 2011). LA neurons project to the BA, and both LA and BA neurons project directly and indirectly to the CE (Herry et al., 2010). Fear expression is regulated by multiple circuits involving the $\mathrm{BA}, \mathrm{CE}, \mathrm{mPFC}$, and periaqueductal gray (Herry and Johansen, 2014). At the cellular level, parvalbumin (PV)-expressing interneurons tightly regulate the activity of the glutamatergic principal neurons within the amygdala (Wolff et al., 2014). This ongoing synaptic inhibition controls whether inputs to the principal neurons undergo synaptic plasticity, allowing the formation of new 
fear memories (Ehrlich et al., 2009). Both presynaptic and postsynaptic KARs contribute to induction of long-term potentiation (LTP) in the LA and BA (Li et al., 2001; Ko et al., 2005; Shin et al., 2010; Cho et al., 2011). Mice lacking the Grik2 gene, encoding the GLUK2 subunit of KAR, have reduced cued and contextual memory recall after fear conditioning indicating impaired fear memory consolidation (Ko et al., 2005). Thus, regulation of synaptic plasticity in the amygdala via PV interneurons and KARs may modulate fear-related behaviors.

PV interneuron maturation and plasticity are influenced by perineuronal nets (PNNs; Beurdeley et al., 2012; Wang and Fawcett, 2012). PNNs are specialized extracellular matrix structures that stabilize synaptic connections onto neurons they surround (Wang and Fawcett, 2012) and are considered as a mark of synaptic stability and consolidated memory (Lorenzo Bozzelli et al., 2018). They prevent LTP at excitatory synapses in the hippocampus (Carstens et al., 2016) and protect fear memories from erasure during extinction in the amygdala (Gogolla et al., 2009; Gunduz-Cinar et al., 2019). Consequently, the number of PV cells surrounded by PNN is used as a marker of neuronal plasticity (Nowicka et al., 2009; Umemori et al., 2018). Within the PV-positive $\left(\mathrm{PV}^{+}\right)$cells, the intensity of PV immunoreactivity increases during development (Donato et al., 2013; Umemori et al., 2015) and is suggested to be an indicator of neuronal maturity (Umemori et al., 2018).

NETO2 regulates interneuron function in the developing hippocampus (Wyeth et al., 2017), where it is also developmentally downregulated (Orav et al., 2017). Thus, we asked whether Neto2 influences interneuron maturation in the amygdala with consequences on fear memory. We studied the PV staining intensity and the number of PV cells surrounded by $\mathrm{PNN}\left(\mathrm{PV}^{+} \mathrm{PNN}^{+}\right)$as markers of amygdala PV interneuron network maturity in juvenile postnatal day (P)23 mice and in 12-week-old adult mice. Following our finding that in adult, but not in the $\mathrm{P} 23$, mice, the fraction of $\mathrm{PV}^{+} \mathrm{PNN}^{+}$cells relative to the total $\mathrm{PNN}^{+}$population was reduced and that the PV staining intensity was lower in Neto2 $2^{-1-}$ compared with Neto2 ${ }^{+/+}$mice, we conducted electrophysiological recordings in the amygdala neurons and measured amygdalar activation after fear acquisition and extinction using c-Fos immediate early gene mapping. Our results indicate that NETO2 deficiency perturbs excitability of the BA, and that defects in these functions may contribute to the higher fear expression and delayed extinction of $\mathrm{Neto}^{-/-}$ mice.

\section{Materials and Methods}

\section{Animals}

Neto $2^{-1-}$ mice were created as previously described (Tang et al., 2011). Mice were maintained on a 12/12 h light/dark cycle (lights on at 6 A.M.) in individually ventilated cages (Mouse IVC Green Line, overall dimensions $391 \times 199 \times 160 \mathrm{~mm}$, floor area $501 \mathrm{~cm}^{2}$; Tecniplast) with free access to water and food. Mice were single housed in IVCs one week before and during the test period to avoid possible effects of social hierarchy on behavior. All animal procedures were performed in accordance with the University of Helsinki animal care committee's regulations. Experimenter was blind to the genotype during all experiments.

\section{Cued fear conditioning and extinction}

Male and female mice were on average 12 weeks old (range 10-15 weeks) during fear conditioning. Testing was performed between 8 A.M. and 3 P.M. to avoid possible effects of the corticosterone secretion peak at the beginning of the dark phase (6 P.M.). Animals were brought in the testing room $30 \mathrm{~min}$ before the beginning of the test session. Cued fear conditioning and extinction were performed as previously described (Fitzgerald et al., 2015). Fear acquisition was performed in context $A$, a square transparent chamber $(23 \times 23 \times 35 \mathrm{~cm})$ with a grid floor delivering the foot shock [unconditioned stimulus (US), $0.6 \mathrm{~mA}$ ], which was cleaned with ethanol between animals. The chamber was inside a white, constantly illuminated (100-lux) box, which contained loudspeakers delivering constant background noise $(68 \mathrm{~dB})$ and the sound cue [conditioned stimulus (CS), sine waves (pure sound) of $10 \mathrm{kHz}, 76 \mathrm{~dB}$, pulsed at $5 \mathrm{~Hz}$. During the acquisition on the first day, a sound cue (CS, $30 \mathrm{~s}$ ) followed by a foot shock (US, $2 \mathrm{~s}$ ) was delivered three times [intertrial interval (ITI) $30 \mathrm{~s}$ after a 120-s habituation period]. Mice remained in the chamber for $160 \mathrm{~s}$ after the last CS-US pairing. On the second day, fear extinction was conducted by presenting $20 \mathrm{CS}$ without foot shocks $(20 \times 30 \mathrm{~s}$ after a 180-s habituation period, ITI 5 s) in context B, a square black chamber $(23 \times 23 \times 35 \mathrm{~cm})$ wherein the grid floor was covered, which was cleaned between animals with water containing $1 \%$ vanilla extract. Experiments were conducted using a computer-controlled fear conditioning system (TSE), and percent time freezing was measured automatically by an infrared detection system. Percent time freezing during extinction was analyzed as an average of four CS presentations. For the c-Fos staining, two groups of adult mice were killed exactly $90 \mathrm{~min}$ after the end of the acquisition [wild type (WT) $n=8$, knock-out (KO) $n=7$ ] or the extinction (WT $n=10$, KO $n=10$; Fig. $6 A$ ).

\section{Immunohistochemistry (IHC)}

Mice were injected with a lethal dose $(600 \mathrm{mg} / \mathrm{kg})$ of pentobarbital (Mebunat Vet $60 \mathrm{mg} / \mathrm{ml}$, Orion Pharma) and transcardially perfused with PBS (137 mM NaCl, $2.7 \mathrm{~mm} \mathrm{KCl,} 10$ $\mathrm{mm} \mathrm{Na}_{2} \mathrm{HPO}_{4} 2 \mathrm{H}_{2} \mathrm{O}$, and $1.8 \mathrm{mM} \mathrm{KH}_{2} \mathrm{PO}_{4} ; \mathrm{pH} 7.4$ ), followed by $4 \%$ paraformaldehyde (PFA) in PBS, both at $37^{\circ} \mathrm{C}$. Brains were post fixed $2-4 \mathrm{~d}$ in PFA at $4^{\circ} \mathrm{C}$, dehydrated, and embedded in paraffin blocks and sectioned $(10 \mu \mathrm{m})$ using a Leica RM2255 microtome (Leica Biosystems). Sections were deparaffinized and rehydrated before heat-induced antigen retrieval $(0.01 \mathrm{~m}$ sodium citrate, Tween $0.05 \%$, $\mathrm{pH}$ 6.0, heated in microwave oven for $15 \mathrm{~min})$. Sections were washed using PBS $+0.2 \%$ Triton $\mathrm{X}-100$ (PBST) for $3 \times 5 \mathrm{~min}$ and incubated $60 \mathrm{~min}$ with blocking solution containing 10\% normal goat serum (NGS; 005-000-121, Jackson ImmunoResearch) in PBST for c-Fos staining, and 
3\% BSA (001-000-162, Jackson ImmunoResearch) + 10\% NGS in PBST for PV and PNN staining. Sections were then incubated 24-48 $\mathrm{h}$ with rabbit anti-c-Fos $(1: 500$, sc-52, Santa Cruz Biotechnology) primary antibody in 5\% NGS in PBST, or with mouse anti-PV (1:5000, PV235, Swant Swiss antibodies) primary antibody, and Wisteria floribunda agglutinin (WFA; detects chondroitin sulfate chains enriched in PNNs) conjugated with biocytin (1:400, L1516, SigmaAldrich) in $0.2 \%$ BSA $+10 \%$ NGS in PBST. Sections were washed $3 \times 5$ min with PBST and, depending on the primary antibody, incubated for 1-2 $\mathrm{h}$ with goat anti-rabbit secondary antibody conjugated with Alexa Fluor 568 (A-11011, ThermoFisher Scientific) or goat anti-mouse secondary antibody conjugated with Alexa Fluor 488 (A-11029, ThermoFisher). WFA-biocytin was detected using streptavidin conjugated with Alexa Fluor 568 (S11226, ThermoFisher Scientific) in PBST. Sections were rinsed $3 \times 5$ min with PBS and mounted using VECTASHIELD Antifade Mounting Medium with DAPI (VECTOR Laboratories).

\section{Imaging and IHC data analysis}

Brain sections were imaged using a Zeiss fluorescent microscope (Axio Imager 2, Carl Zeiss) and processed and exported with the Zeiss Zen Lite Software (Carl Zeiss). For c-Fos and PV/WFA staining, images were analyzed with a semi-automated macro in ImageJ (manual settings: region of interest selection, counting of PNN/PVpositive cells, PV staining intensity) and without adjusting for exposure time and background before the analysis. PV intensity was calculated from the integrated density (area*mean gray value) of PV staining normalized by the intensity of the background near the PV cell soma. A cell was considered c-Fos ${ }^{+}$if it co-localized $>75 \%$ with nuclear DAPI staining. c-Fos intensity was calculated using the area $\left(\mu \mathrm{m}^{2}\right) *$ mean gray value of each positive c-Fos cell (integrated density) and normalized by the integrated density of the background from the selected regions of interest.

\section{Electrophysiological recordings}

We prepared $350-\mu \mathrm{m}$ coronal acute slices from brains of 12 -week-old Neto2 ${ }^{+/+}$and Neto2 ${ }^{-/-}$littermate mice. During the dissection and slicing, the brain was kept in an ice-cold solution containing the following: $87 \mathrm{~mm} \mathrm{NaCl}$, $2.5 \mathrm{~mm} \mathrm{KCl}, 7 \mathrm{~mm} \mathrm{MgCl}, 1.25 \mathrm{~mm} \mathrm{NaH}_{2} \mathrm{PO}_{4}, 0.5 \mathrm{~mm}$ $\mathrm{CaCl}_{2}, 25 \mathrm{~mm} \mathrm{NaHCO}_{3}, 50 \mathrm{~mm}$ D-sucrose, and $25 \mathrm{~mm} \mathrm{D-}$ glucose (all from Sigma-Aldrich) and saturated with 95\% $\mathrm{O}_{2}$ and $5 \% \mathrm{CO}_{2}$. Immediately after cutting the slices were transferred to ACSF containing the following: $124 \mathrm{~mm}$ $\mathrm{NaCl}, 3 \mathrm{~mm} \mathrm{KCl}, 1.25 \mathrm{~mm} \mathrm{NaH}_{2} \mathrm{PO}_{4}, 1 \mathrm{~mm} \mathrm{MgSO}$, $26 \mathrm{~mm}$ $\mathrm{NaHCO}_{3}$, $15 \mathrm{~mm}$ D-glucose, $2 \mathrm{~mm} \mathrm{CaCl}$; $5 \% \mathrm{CO}_{2} / 95 \%$ $\mathrm{O}_{2}$ and incubated $30 \mathrm{~min}$ at $+35^{\circ} \mathrm{C}$ and $30 \mathrm{~min}$ to $5 \mathrm{~h}$ at room temperature before use.

For recordings, the slice was placed in a submerged recording chamber and continuously perfused with ACSF at $+30^{\circ} \mathrm{C}$. Whole-cell voltage-clamp recordings were made from $L A$ and BA under visual guidance using patch electrodes with resistance of 4-6 $\mathrm{M} \Omega$. Uncompensated series resistance (Rs) was monitored by measuring the peak amplitude of the current response to a 5-mV step. Only experiments where Rs $<30 \mathrm{M} \Omega$, and with $<20 \%$ change in Rs during the experiment, were included in the analysis. In addition, cells with very low capacitance $(<35 \mathrm{pF})$ were considered as GABAergic interneurons and excluded from the analysis.

For recording of spontaneous synaptic currents, patch pipette was filled with a solution containing the following: $135 \mathrm{~mm}$ K-gluconate, $10 \mathrm{~mm}$ HEPES, 2 mм KCl, $2 \mathrm{~mm} \mathrm{Ca}$ $(\mathrm{OH})_{2}, 5 \mathrm{~mm}$ EGTA, $4 \mathrm{~mm} \mathrm{Mg}$-ATP, and $0.5 \mathrm{~mm}$ Na-GTP; 285 mOsm and $\mathrm{pH}$ was adjusted to 7.2 with $\mathrm{NaOH}$ (all from Sigma-Aldrich). Spontaneous glutamatergic events (sEPSCs) were recorded at a holding potential of $-70 \mathrm{mV}$, after which the cell was voltage clamped at $0 \mathrm{mV}$ to record spontaneous GABAergic currents (sIPSCs). mEPSC recordings were made with an intracellular solution containing the following: $130 \mathrm{~mm} \mathrm{CsMeSO}_{4}, 10 \mathrm{~mm}$ HEPES, 0.5 mм EGTA, 4 mм Mg-ATP, 0.3 mм Na-GTP, 5 mм QX-314, and $8 \mathrm{~mm} \mathrm{NaCl} ; 285 \mathrm{mOsm}$ and $\mathrm{pH}$ was adjusted to 7.2 with $\mathrm{CsOH}$ (all from Sigma-Aldrich). mEPSCs were recorded in the presence of $1 \mu \mathrm{M}$ TTX (Abcam), $100 \mu \mathrm{M}$ Picrotoxin (Abcam), and $50 \mu \mathrm{m}$ AP5 (HelloBio) at a holding potential of $-70 \mathrm{mV}$. mIPSC recordings were made with an intracellular solution containing the following: $145 \mathrm{~mm}$ $\mathrm{CsCl}, 10 \mathrm{~mm}$ HEPES, $5 \mathrm{~mm}$ EGTA, $2 \mathrm{~mm} \mathrm{MgCl}_{2}$, $2 \mathrm{~mm}$ $\mathrm{CaCl}_{2}$, $4 \mathrm{~mm} \mathrm{Mg-ATP}$, and $0.33 \mathrm{~mm}$ Na-GTP; $278 \mathrm{mOsm}$ and $\mathrm{pH}$ was adjusted to 7.2 with $\mathrm{CsOH}$ (all from SigmaAldrich). mIPSCs were recorded in the presence of $50 \mu \mathrm{M}$ AP5 (HelloBio), $25 \mu \mathrm{M}$ GYKI53655 (Tocris), $1 \mu \mathrm{M}$ TTX (Abcam) at a holding potential of $-70 \mathrm{mV}$. Biocytin $(0.3 \%$; Sigma-Aldrich) was added to both intracellular solutions to later visualize and analyze cell morphology and to confirm the location of the recorded neuron. Data were collected using WinLTP software (WinLTP Ltd) and analyzed offline using the MiniAnalysis 6.0.3 program (Synaptosoft Inc.). The threshold for detection of both inward (sEPSC, mEPSC, mIPSC) and outward (sIPSC) events was three times the baseline noise level, and all detected events were verified visually. The experimenter was blind to the mouse genotype throughout the experiment until statistical analysis.

\section{Biocytin staining and spine analysis}

After filling the recorded neurons with biocytin, the slices were fixed with 4\% PFA in PBS. The fixed slices were washed first with PBS, then with PBS + 0.3\% Triton $X-100$ solution (PBST) and blocked in $0.4 \%$ NGS in PBST. Biocytin was visualized using streptavidin conjugated with Alexa Fluor 488 (Invitrogen). Slices were mounted using VECTASHIELD Hard Set Antifade Mounting Medium with DAPI (VECTOR Laboratories). First branch dendrites of the neurons were imaged using Zeiss LSM 700 Confocal microscope $(63 \times$ objective, 2.6 zoom, interval of stacked images $0.25 \mu \mathrm{m}$, Axio Imager 2, Carl Zeiss), and the images were processed and exported with Zeiss Black Software (Carl Zeiss). Spine density was measured post hoc from primary branches and analyzed using NeuronStudio software (Computational Neurobiology and Imaging Center, Mount Sinai School of Medicine, NY). Spines were classified as mushroom, thin, or stubby 
Table 1: Statistical table

\begin{tabular}{llll}
\hline Figure & Data structure & Statistical test & Significance threshold $(\alpha)$ \\
\hline $1 B-E$ & Normally/not normally distributed & Generalized estimating equation (GEE) & $<0.05$ \\
$2 A, B$ & Not normally distributed & Two sample Kolmogorov-Smirnov test & $<0.05$ \\
$2 C-E$ & Not normally distributed & Generalized estimating equation (GEE) & $<0.05$ \\
$3 A-D$ & Normally/not normally distributed & Two sample Kolmogorov-Smirnov test & $<0.05$ \\
& & Generalized estimating equation (GEE) & $<0.05$ \\
$4 A, B$ & Bimodally distributed & Two sample Kolmogorov-Smirnov test & $<0.05$ \\
$4 C-F$ & Normally distributed & Generalized estimating equation (GEE) & $<0.05$ \\
$5 A, B$ & Normally distributed & Two sample Kolmogorov-Smirnov test & $<0.05$ \\
$5 A-E$ & Normally/not normally distributed & Generalized estimating equation (GEE) & $<0.05$ \\
$6 B$ & Normally distributed & Mixed ANOVA (repeated measures) & $<0.05$ \\
$6 E-H$ & Normally/not normally distributed & Generalized estimating equation (GEE) & $<0.05$ \\
\hline
\end{tabular}

using NeuronStudio spine classifier settings. Briefly, if no neck was present, spine was classified as stubby, and in the case a neck was present, the head size diameter threshold was used to distinguish between thin and mushroom spines $(<0.35 \mu \mathrm{m}$ for thin and $>0.35 \mu \mathrm{m}$ for mushroom). Length and thickness of dendrites were measured using NeuronStudio software neurites and measurement tools, respectively. The experimenter was blind to the mouse genotype throughout the experiment until statistical analysis.

\section{Statistical analysis}

Neto2 ablation influences fear expression and extinction in both male and female mice (Mennesson et al., 2019), and therefore, we included both sexes in this study. Because of absence of sex effects in the behavioral data, we analyzed males and females jointly in all experiments. Dependent variables were checked for normal distribution (Shapiro-Wilk test, $p>0.05$ ) and were analyzed using mixed ANOVA, generalized estimating equation (GEE), or Kolmogorov-Smirnov tests (Table 1). GEE analysis was used to control for within-subject dependencies of individual data points collected from the same animal (e.g., neurons recorded from slices originating from the same mouse) or from the same cell/image (e.g., PV cell intensities measured from the same image), as previously described (Hanley et al., 2003; Laine et al., 2018). Statistical analyses were conducted using SPSS Statistics 24 (IBM), GraphPad Prism7 (GraphPad Software), or RStudio (RStudio Inc.).

\section{Results}

\section{PV interneuron state of the $\mathrm{Neto2}^{-/-}$amygdala}

Neto2 ${ }^{-/-}$mice have increased fear expression and delayed extinction in cued fear conditioning compared with the Neto2 $2^{+/+}$mice (Mennesson et al., 2019). Since the amygdala is the key brain region for processing of sensory information related to fear and anxiety, and in consolidation of fear memories, we asked whether NETO2 regulates development and function of the amygdala. We first investigated well-established molecular markers of maturity and plasticity involved in fear memory consolidation, the number of PNNs and PV-expressing interneurons (Gogolla et al., 2009; Donato et al., 2013, 2015). We concentrated on the LA and BA, the targets of subcortical projections from the acoustic thalamus. Since the number of PNNs increase during development, we studied two time points, P23 (juveniles) and $\sim 12$ weeks (adults). The juvenile time point is of interest because P23 mice have stronger fear expression during cue retrieval (Pattwell et al., 2011) and faster fear extinction of cued fear memory than adults (Pattwell et al., 2012). We quantified the number of $\mathrm{PNN}^{+}, \mathrm{PV}^{+}$, and double positive $\mathrm{PV}^{+} \mathrm{PNN}^{+}$cells (Fig. $1 A-D$ ) and calculated the percentage of $\mathrm{PV}^{+} \mathrm{PNN}^{+}$ cells relative to the total population of $\mathrm{PNN}^{+}$or $\mathrm{PV}^{+}$cells, as previously (Karpova et al., 2011; Ohira et al., 2013; Guirado et al., 2014; Fig. 1E). Overall, we found a larger number of $\mathrm{PNN}^{+}$than $\mathrm{PV}^{+}$cells, and only a subset of $\mathrm{PNN}^{+}$cells were also $\mathrm{PV}^{+}$in the LA/BA (Fig. 1A), as reported previously (Morikawa et al., 2017). As expected (Gogolla et al., 2009; Nowicka et al., 2009; Umemori et al., 2015), we detected a larger number of $\mathrm{PNN}^{+}(p=1.4 \mathrm{E}-$ $11), \mathrm{PV}^{+}(p=0.013)$, and $\mathrm{PV}^{+} \mathrm{PNN}^{+}(p=0.0001)$ cells in the adult compared with juvenile WT mice (Fig. 1B-D). However, in the Neto2 ${ }^{-1-}$ mice, the abundance of $\mathrm{PV}^{+}$ and $\mathrm{PV}^{+} \mathrm{PNN}^{+}$did not differ between juveniles and adults, and only the number of the $\mathrm{PNN}^{+}$cells was significantly higher in adults than juveniles $\left(\mathrm{PNN}^{+} p=0.0016, \mathrm{PV}^{+}\right.$ $p=0.29, \mathrm{PV}^{+} \mathrm{PNN}^{+} p=0.12$; Fig. $\left.1 B-D\right)$. Yet, the number of $\mathrm{PNN}^{+}, \mathrm{PV}^{+}$, and $\mathrm{PV}^{+} \mathrm{PNN}^{+}$cells did not differ significantly between $\mathrm{Neto}^{-/-}$and $\mathrm{Neto}^{+/+}$mice in either juvenile or adult time points (Fig. $1 B-D$ ). However, there was a trend for reduced numbers of $\mathrm{PV}^{+} \mathrm{PNN}^{+}$cells in adult Neto2 ${ }^{-1-}$ compared with $\mathrm{Neto}^{+/+}$mice $\left(\mathrm{PV}^{+} \mathrm{PNN}^{+}, p=0.054\right.$; Fig. $\left.1 D\right)$. Adult Neto2 ${ }^{+/+}$mice had more $\mathrm{PV}^{+} \mathrm{PNN}^{+}$cells compared with juvenile Neto2 ${ }^{+/+}$ mice relative to both $\mathrm{PNN}$ and $\mathrm{PV}$ cell populations $(p=0.046$ and $p=0.004$, respectively), while no differences were detected between ages in Neto $2^{-1-}$ mice (Fig. $1 E$ ). Neto $2^{-1-}$ adult, but not juvenile mice, had a significantly lower percentage of $\mathrm{PV}^{+} \mathrm{PNN}^{+}$cells within the total PNN population compared with $\mathrm{Neto}^{+/+}$mice $(p=0.003$; Fig. 1E). Altogether, these results suggest defects in the maturation of PV interneurons in Neto ${ }^{-1-}$ mice between P23 and adult ages.

To further investigate the maturation of the PV inhibitory network within the LA/BA, we measured PV staining intensity (Fig. 2). Donato et al. (2013) have established that the intensity of PV staining indicates the maturity level of hippocampal neurons, where immature cells have lower PV intensity than mature cells (Donato et al., 2013). We 
A Juvenile $\mathrm{Neto}^{+/+}$
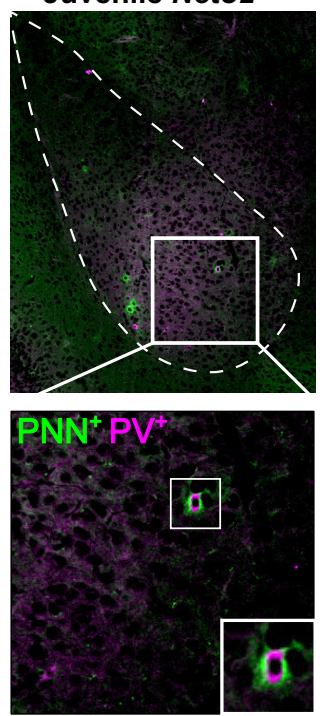

B
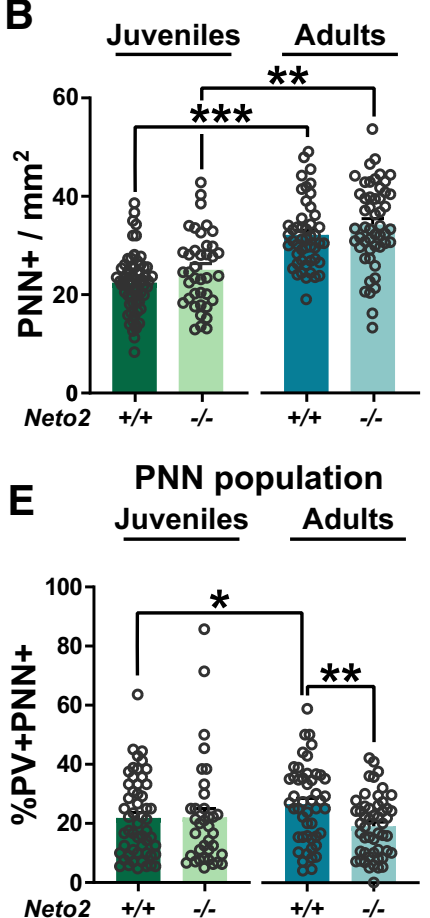

Juvenile Neto ${ }^{-1-}$
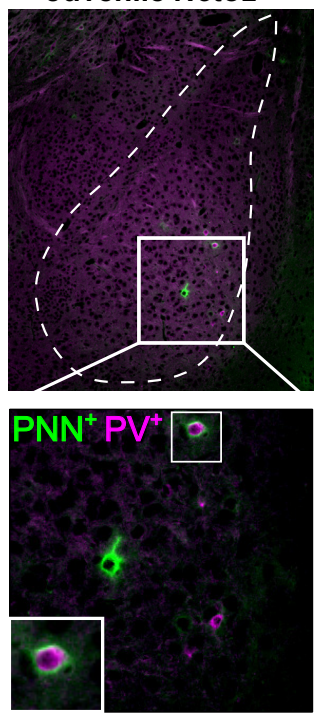

C Juveniles Adults
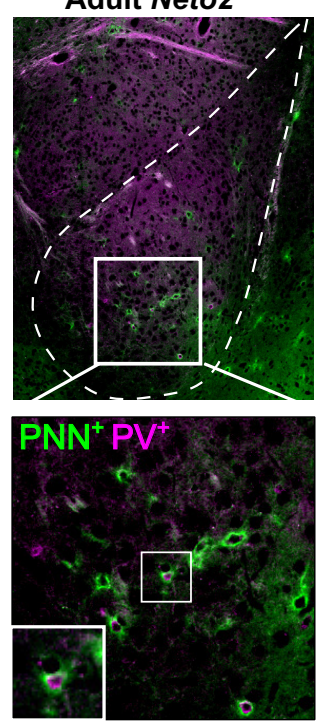

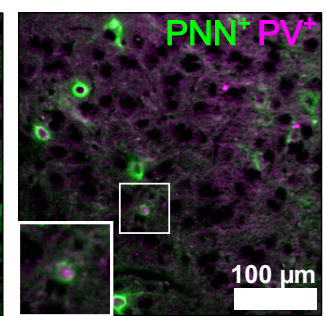

Adult Neto2-1-

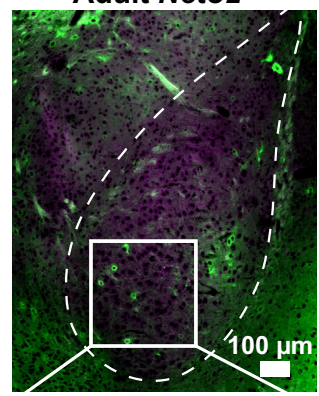

D Juveniles Adults
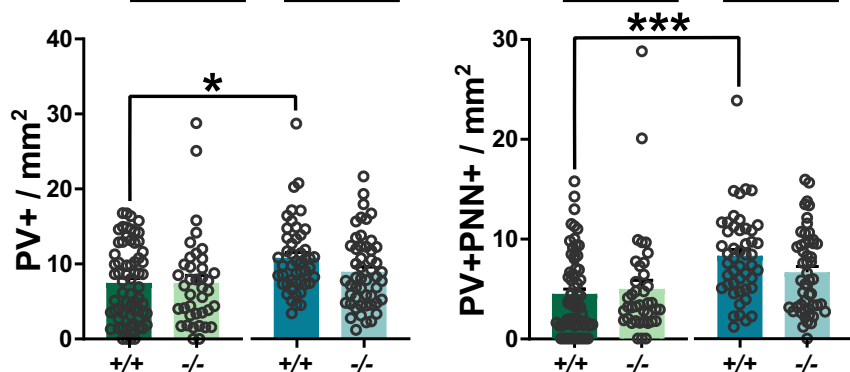

PV population

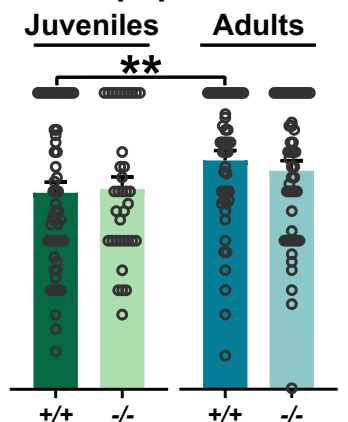

Figure 1. PV interneuron state of the Neto2 ${ }^{-/-}$amygdala. $\boldsymbol{A}$, Representative images of WFA (PNN) and PV staining in the amygdala of juvenile and adult mice. Examples of double positive cells are marked with a white square and corresponding close-ups are shown. Abundance of $(\boldsymbol{B}) \mathrm{PNN}^{+},(\boldsymbol{C}) \mathrm{PV}^{+}$, and $(\boldsymbol{D}) \mathrm{PV}^{+} \mathrm{PNN}^{+}$cells in the amygdala of juvenile and adult mice. E, Percentage of $\mathrm{PV}^{+} \mathrm{PNN}^{+}$double positive cells in the total $\mathrm{PNN}^{+}$cell population and total $\mathrm{PV}^{+}$cell population. Each dot represents data from one image. Mean \pm SEM is shown. Genotype effect calculated using GEE analysis; $* p<0.05$, $* * p<0.01, * * * p<0.001$.

first visualized the frequency of LA/BA cells as a function of their PV staining intensity. We did not observe differences in the distributions between juvenile $\mathrm{Neto}^{-1-}$ and Neto2 ${ }^{+/+}$mice (Fig. $2 A, p=0.60$ ), while the distribution of the adult $\mathrm{Neto}^{-/-}$mice was shifted toward low PV intensity levels compared with $\mathrm{Neto}^{+/+}$mice (Fig. 2B, $p=8.94 \mathrm{E}-5)$. As expected, juvenile mice had lower mean PV intensity levels compared with adult mice $\left(\mathrm{Neto}^{+/+}\right.$ $p=4.1 \mathrm{E}-11$ and $\mathrm{Neto}^{-/-} p=0.008$; Fig. 2C). Crucially, PV intensity was significantly lower in adult, but not in juvenile, Neto2 ${ }^{-1-}$ compared with Neto2 ${ }^{+/+}$mice (Fig. 2C, $p=0.012$ ). Because LA and BA PV interneurons may differentially influence fear learning (Lucas et al., 2016), we further investigated PV staining intensity separately in the LA and BA. BA had more PV ${ }^{+}$cells $\left(92-95 \%\right.$ of all $\mathrm{PV}^{+}$ cells) than LA, and reduced PV intensity was only 
A

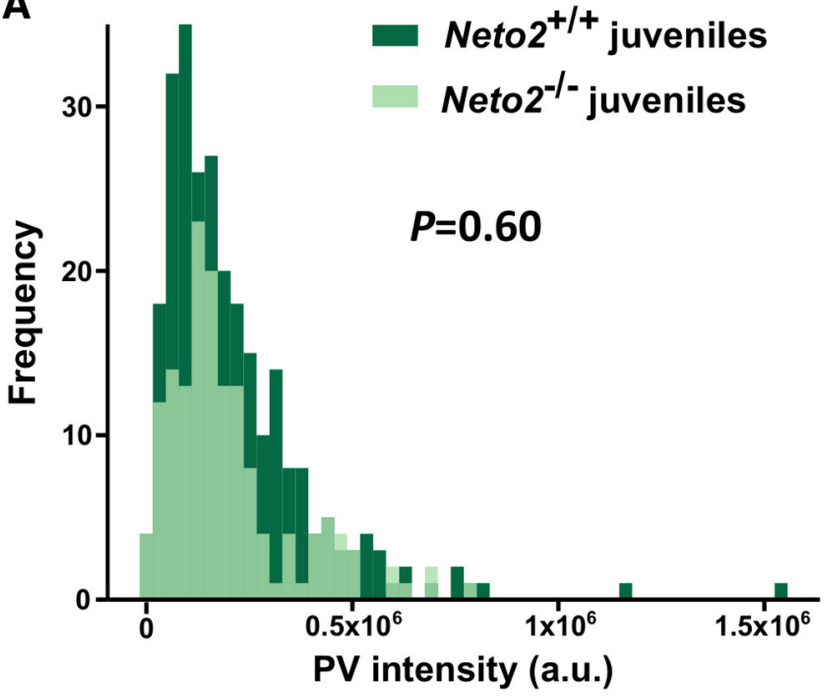

B

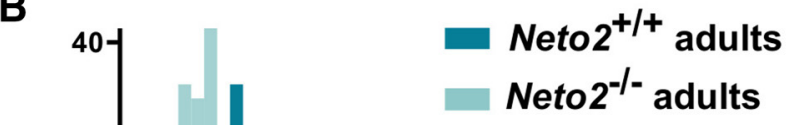

$P=8.95 \times 10^{-5}$
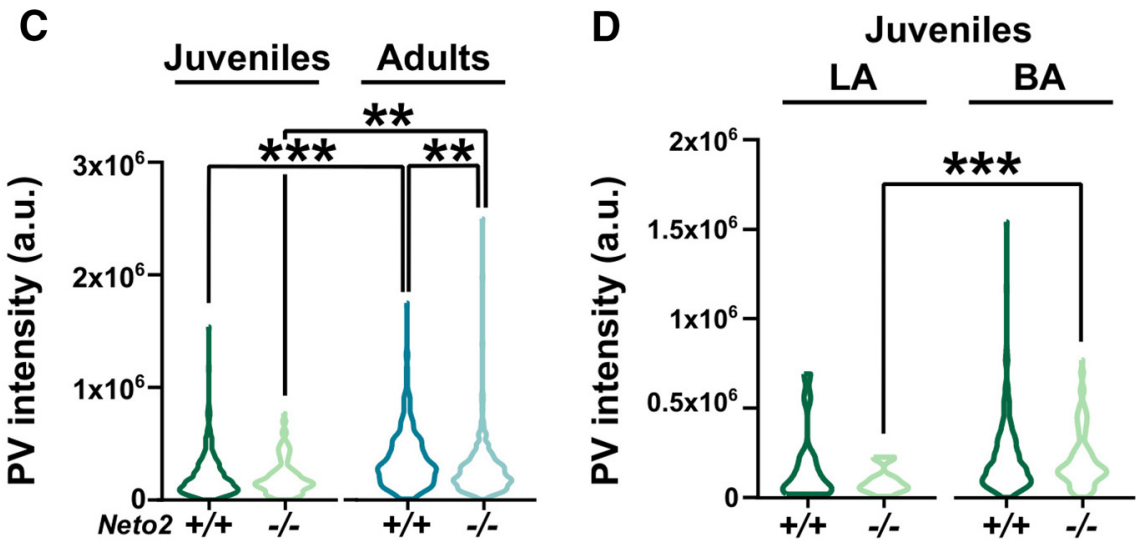

E

Adults

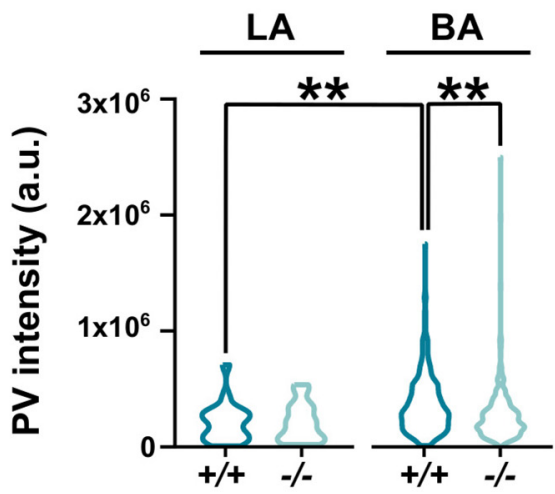

Figure 2. PV interneuron intensity is reduced in adult Neto $2^{-/-}$amygdala. PV intensity distribution in Neto2-/- and Neto2 $2^{+/+}$mice at $(\boldsymbol{A})$ juvenile and $(\boldsymbol{B})$ adult age. Mean PV intensity in the LA/BA $(\boldsymbol{C})$ and in the LA and BA nuclei analyzed separately at $(\boldsymbol{D})$ juvenile and $(\boldsymbol{E})$ adult age. Mean \pm SEM is shown. Genotype effect calculated using Kolmogorov-Smirnov $(\boldsymbol{A}, \boldsymbol{B})$ or GEE $(\boldsymbol{C}-\boldsymbol{E})$ analysis; $* * p<0.01, * * * p<0.001$.

observed in the BA, but not in the LA of adult Neto2 ${ }^{-1-}$ mice (adult Neto2 $2^{-/-}$vs Neto ${ }^{+/+}$LA: $p=0.99$, BA: $p=0.002$; Fig. $2 D, E$ ). Taken together, these results indicate that NETO2 is required for proper maturation of the BA PV inhibitory network.

\section{Increased excitability and spine density in the $\mathrm{Neto}^{-/}$ - BA}

To study whether the PV inhibitory network differences between adult $\mathrm{Neto}^{-/-}$and $\mathrm{Neto} 2^{+/+}$mice are associated with changes in the synaptic transmission in the amygdala, we recorded spontaneous glutamatergic and GABAergic synaptic currents (sEPSCs and sIPSCs) in the LA and BA (Fig. 3). Neto $2^{-/-}$and Neto $2^{+/+}$mice did not differ in either mean amplitude or frequency of sEPSCs or sIPSCs (Fig. 3), or their ratios (excitation-inhibition balance; data not shown).

To test whether dendritic spine density differs between Neto2 ${ }^{-/-}$and $\mathrm{Neto}^{+/+}$mice, we filled the recorded cells from LA and BA with biocytin and quantified spine numbers and densities (Fig. 4). We observed large heterogeneity in the first branch dendrite diameter, the part of the dendritic tree used for the measurements and found them to follow a bimodal distribution both in the LA and BA (Fig. 4A, $B)$. However, these distributions did not differ between Neto2 ${ }^{-1-}$ and Neto $2^{+/+}$mice (Fig. $4 A, B$ ). Because of the bimodal distribution, we examined separately the thin and thick dendrite groups divided by the median of the dendrite thickness. Neto $2^{-/-}$and Neto2 ${ }^{+/+}$mice had similar spine densities in both thin and thick dendrite groups in the LA (Fig. $4 C, D$ ). However, in the BA, spine density was higher in the thin, but not in the thick dendrite group, in Neto ${ }^{-/-}$ compared with $\mathrm{Neto}^{+/+}$mice (all spine classes combined $p=0.003$; Fig. 4E,F). Morphologic classification of spines demonstrated that this increased density was because of a higher number of mushroom and thin spines in Neto2 $2^{-1-}$ compared with $\mathrm{Neto}^{+/+}$mice (mushroom $p=0.006$, thin $p=0.041$; Fig. $4 F$ ).

Because local increased strength of glutamatergic synapses might be compensated on the network level and thus not be detectable in spontaneous activity measurements, 


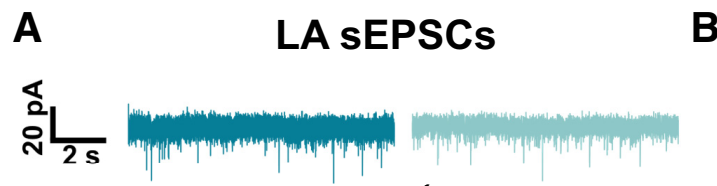

B
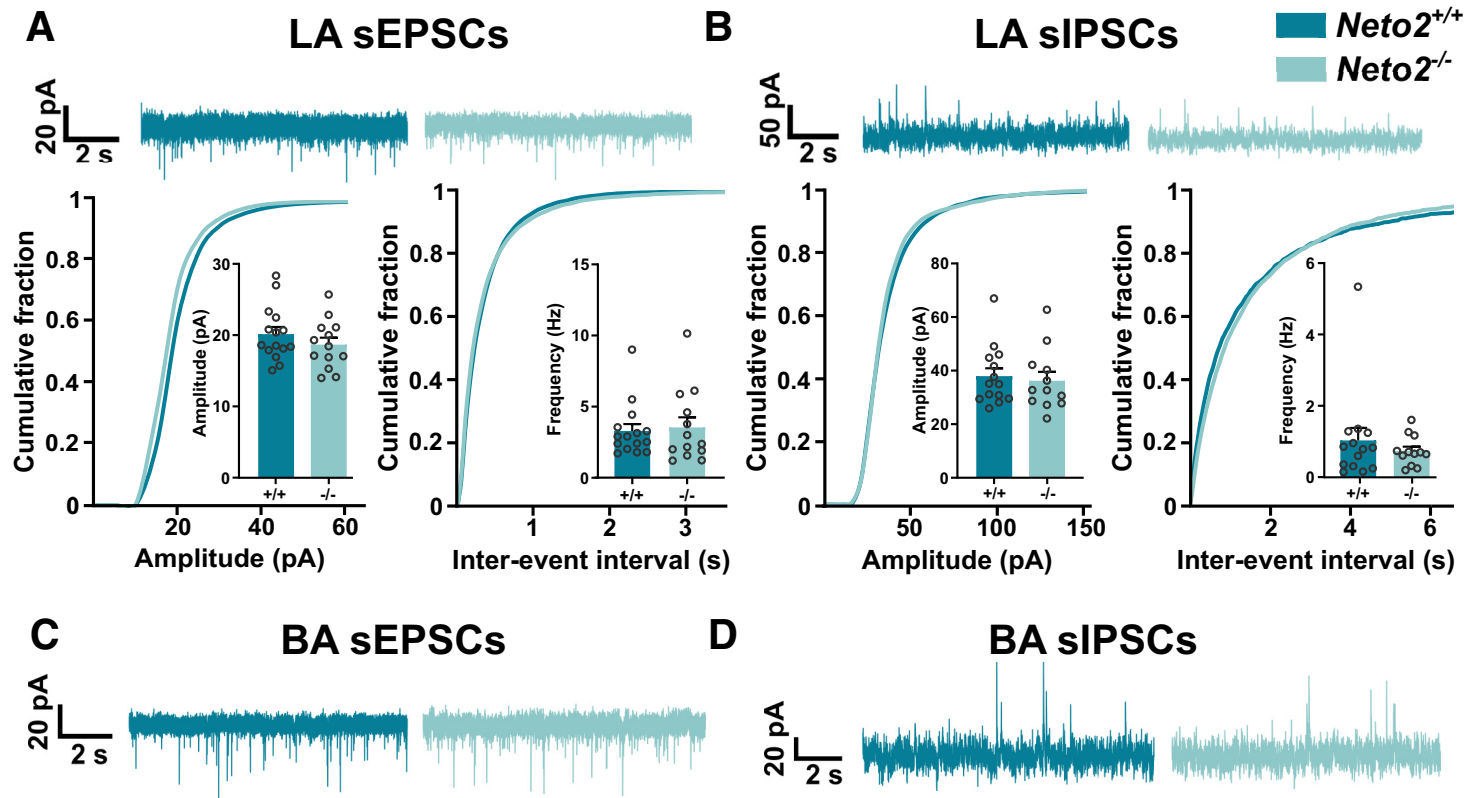

D

BA sIPSCs
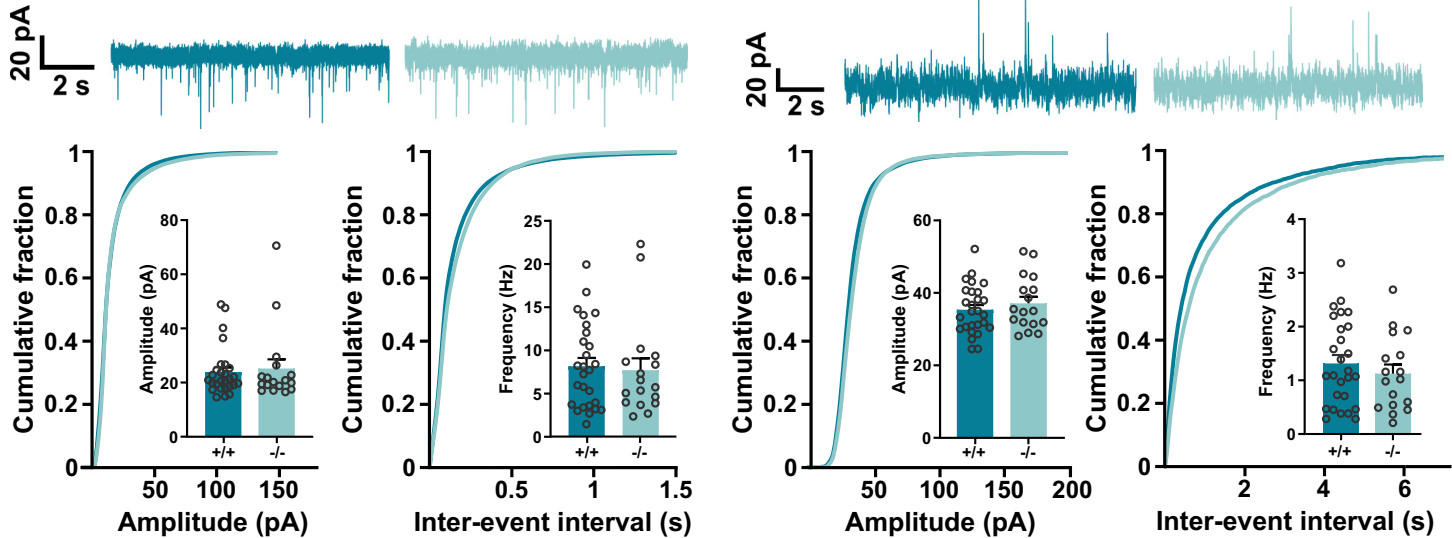

Figure 3. Spontaneous activity of glutamatergic and GABAergic currents in the LA and BA Neto2 ${ }^{-1-}$ amygdala. Representative traces of SEPSC $(\boldsymbol{A})$ and SIPSC $(\boldsymbol{B})$ recordings in the LA of $\mathrm{Neto}^{-/-}$and Neto $2^{+/+}$mice with cumulative fraction and bar graphs for current amplitude and frequency (mice: WT $n=5, \mathrm{KO} n=3$; recorded cells: WT $n=15, \mathrm{KO} n=13$ ). Representative traces of sEPSCs (C) and sIPSCs $(\boldsymbol{D})$ in the BA of Neto2 $2^{-/-}$and Neto2 ${ }^{+/+}$mice with cumulative fraction and bar graphs for current amplitude and frequency (mice: WT $n=6, \mathrm{KO} n=3$; recorded cells: WT $n=27, \mathrm{KO} n=17$ ). Each dot represents one cell. Mean \pm SEM is shown. Genotype effect calculated using two-sample Kolmogorov-Smirnov test (cumulative plots) or GEE analysis (bar graphs).

we measured action potential-independent mEPSCs in the BA (Fig. 5A). Both the mean amplitude and frequency of mEPSCs were higher in Neto2 ${ }^{-/-}$compared with $\mathrm{Neto}^{+/+}$ mice (amplitude $p=0.013$ and frequency $p=0.039$; Fig. $5 A)$. Cumulative plots did not reveal significant differences in the amplitude or frequency distribution of the mEPSCs between Neto2 $2^{-/-}$and Neto $2^{+/+}$mice $(p=0.99$ and $p=0.66$ for amplitude and interevent interval, respectively; Fig. 5A). To test whether the amygdala PV interneuron immaturity observed by $\mathrm{IHC}$ is associated with changes in GABAergic transmission, we measured mIPSCs from BA neurons (Fig. $5 B-E$ ). While the mIPSC amplitude did not differ between $\mathrm{Neto}^{-/-}$and $\mathrm{Neto}^{+/+}$mice, their mean frequency was strongly decreased in the Neto $2^{-1-}$ mice (Fig. 5B, $p=6.5 \mathrm{E}-$ 9) demonstrating either a lower release of GABA or less GABAergic innervation in BA neurons. In addition, the amplitude distribution of mIPSCs was shifted toward low amplitude events in Neto2 ${ }^{-/-}$mice $(p=0.023)$, while their frequency distributions were similar in $\mathrm{Neto}^{-1-}$ and Neto $2^{+/+}$mice (Fig. 5B). We further attempted to discriminate the origin of GABAergic inputs based on mIPSC kinetics. PV interneurons innervate the perisomatic region of amygdala principal neurons and are therefore characterized by fast rise-time (Veres et al., 2017). To elucidate the possible contribution of PV interneurons to GABAergic innervation of BA neurons, we sorted the mIPSCs in 1-ms bins based on rise-time. The relative rise-time distribution of mIPSCs did not significantly differ between $\mathrm{Neto}^{-1-}$ and Neto2 ${ }^{+/+}$mice (Fig. 5C, $p=0.85$ ). We then divided the events into two groups based on their rise-time (Fig. 5D,E). The amplitudes of slow (rise-time $>2 \mathrm{~ms}$ ) and fast rise-time mIPSCs (rise-time $<2 \mathrm{~ms}$ ) were similar in $\mathrm{Neto}^{-1-}$ and Neto ${ }^{+/+}$mice $(p=0.13$ and $p=0.92$, respectively; Fig. $5 D)$. Similarly, the frequency of fast mIPSCs was equal in Neto2 ${ }^{-1-}$ and Neto $2^{+/+}$mice (Fig. $5 E, p=0.22$ ). In contrast, the frequency of slow mIPSCs was significantly lower in Neto2 ${ }^{-/-}$compared with $\mathrm{Neto}^{+/+}$mice (Fig. 5E, $p=0.006$ ), indicating that GABAergic inputs from putative non-PV interneuron subclass is altered in Neto2 ${ }^{-1-}$ mice. Altogether, these results demonstrate higher BA glutamatergic synaptic strength and lower local inhibition in $\mathrm{Neto}^{-1-}$ mice. While our findings suggest impaired GABAergic transmission in 
A

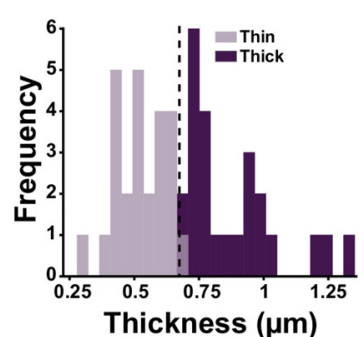

C

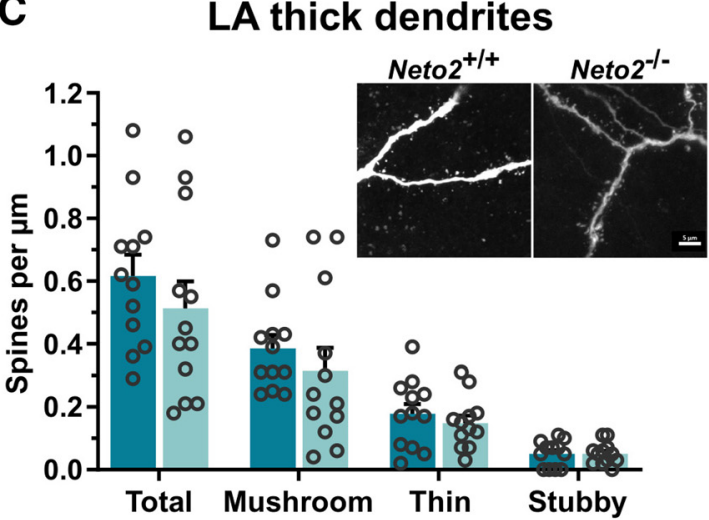

B

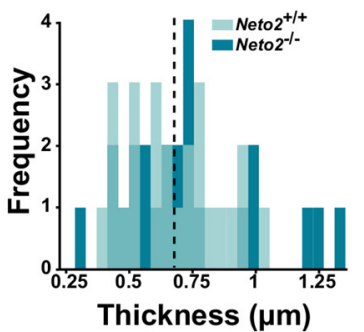

Thickness $(\mu \mathrm{m})$

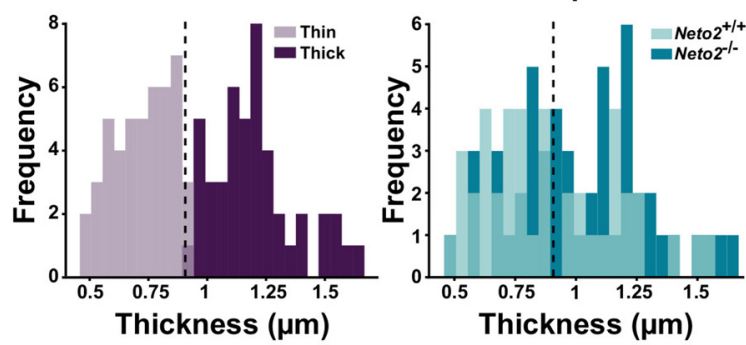

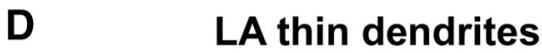

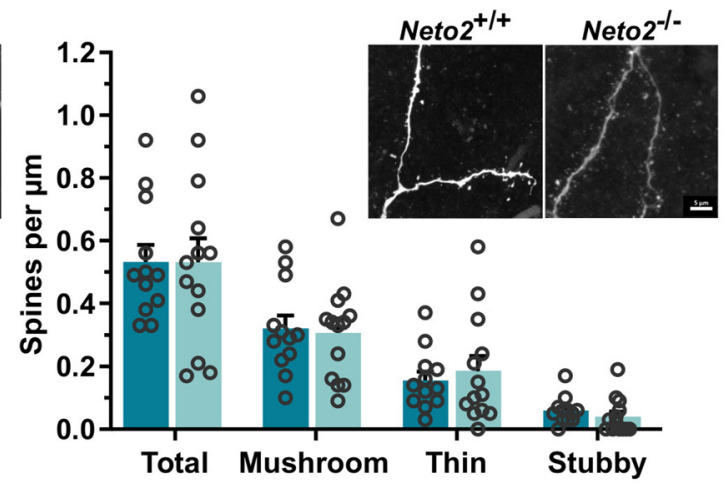

BA thin dendrites
E

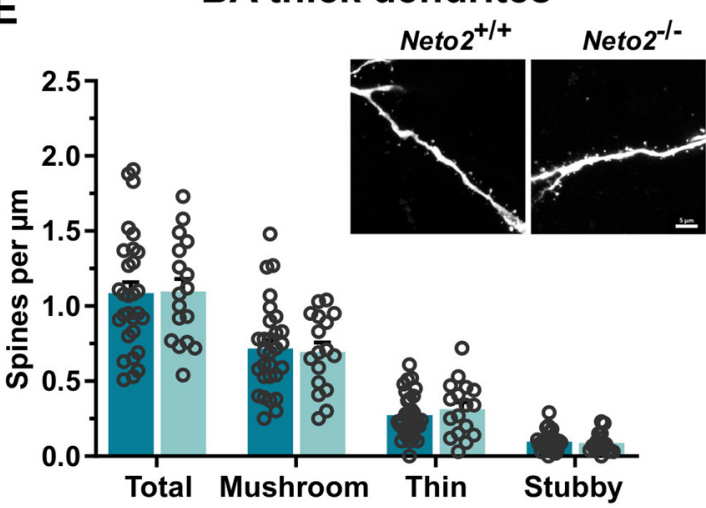

$\mathbf{F}$

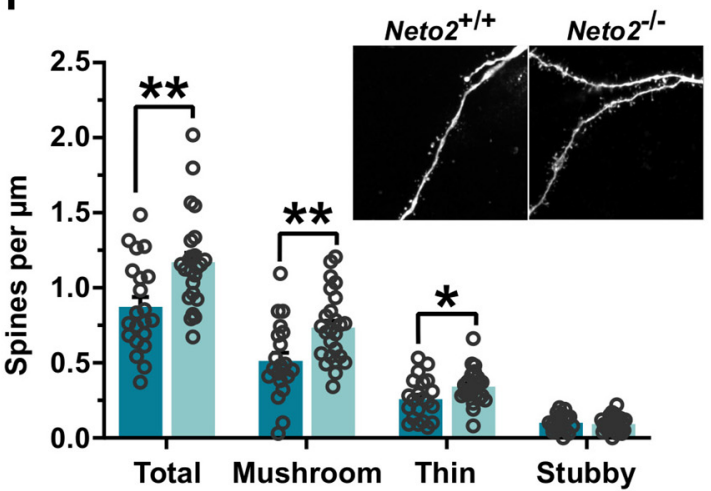

Figure 4. Increased dendritic spine density in the BA of $N e t o 2^{-1-}$ mice. Frequency plot of the dendrite thickness distribution, and di-

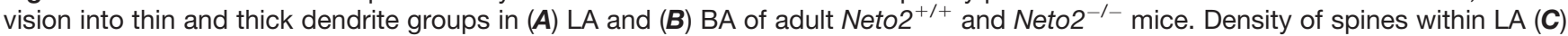
thick (analyzed dendrites: WT $n=12, \mathrm{KO} n=12$ ) and $(\boldsymbol{D})$ thin dendrite groups (analyzed dendrites: WT $n=12, \mathrm{KO} n=13$ ) from adult $\mathrm{Neto}^{-/-}$and $\mathrm{Neto}^{+/+}$mice (mice: WT $n=5, \mathrm{KO} n=3$ ). Density of spines within BA (E) thick (analyzed dendrites: WT $n=29$, KO $n=17$ ) and $(\boldsymbol{F})$ thin dendrite groups (analyzed dendrites: WT $n=21, \mathrm{KO} n=25)$ of Neto2 ${ }^{-1-}$ and Neto2 ${ }^{+/+}$adult mice (mice: WT $n=10$, KO $n=6$ ). Each dot represents one dendrite. Mean \pm SEM is shown. Genotype effect calculated using two-sample Kolmogorov-Smirnov test $(\boldsymbol{A}, \boldsymbol{B})$ or GEE analysis $(\boldsymbol{C}-\boldsymbol{F}) ; * p<0.05, * * p<0.01$.

Neto $2^{-/-}$mice, rise-time analysis of the events suggests that these changes cannot be attributed to perisomatic PV interneurons but mainly involve more distal GABAergic inputs.

\section{Stronger neuronal activation in the $\mathrm{Neto}^{-/-}$ amygdala after fear acquisition}

The amygdala subnuclei function differentially in fear learning and memory. LA and BA receive fear stimuli and store fear memories, respectively, while CE is the output nucleus for defensive behaviors, such as freezing. To investigate neuronal activation of the amygdala after fear acquisition or extinction, we quantified the number of cells expressing the c-Fos immediate early gene in the LA/BA or in the CE in $\mathrm{Neto}^{-/-}$and $\mathrm{Neto}^{+/+}$mice (Fig. 6). At the behavioral level, we replicated the earlier findings (Mennesson et al., 2019) demonstrating that $\mathrm{Neto}^{-1-}$ mice have higher fear expression and impaired extinction compared with $\mathrm{Neto}^{+/+}$mice during cued fear conditioning [acquisition Neto2 ${ }^{-/-}$vs $\mathrm{Neto}^{+/+}$pre-CS: $p=0.59$ and post-CS3: $p=4.54 \mathrm{E}-05$; extinction time (CS) effect: $p=1.28 \mathrm{E}-10$, genotype effect: $p=3.71 \mathrm{E}-05$, time (CS) $\times$ genotype interaction effect: $p=0.00011$. CS $(1-4)$ vs CS (17-20): Neto2 $2^{+/+} p=8.13 \mathrm{E}-05$ and Neto2 ${ }^{-1-} p=0.22$; Fig. 6B]. Neto $2^{-1-}$ mice had a larger number of c-Fos ${ }^{+}$ 
A

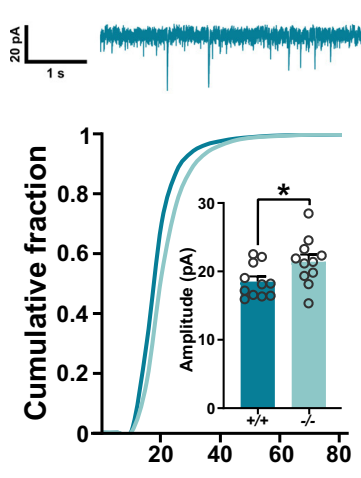

Amplitude (pA)

C

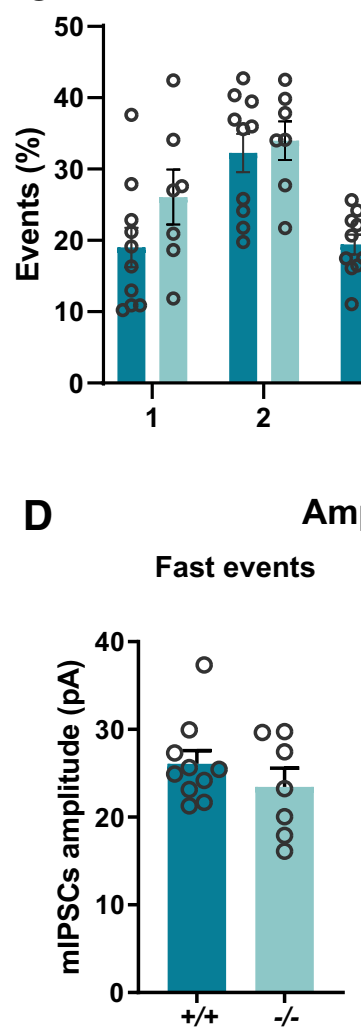

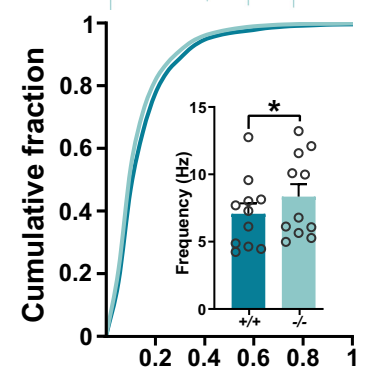

Inter-event interval (s)
B

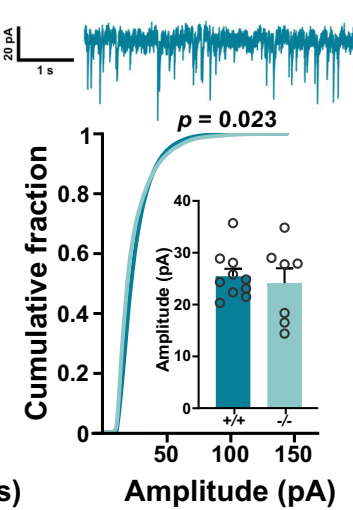

BA mIPSCs

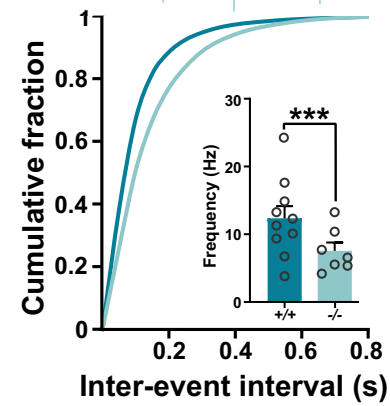

$\mathrm{Neto}^{+/+}$

Neto2 ${ }^{-/-}$ 
A

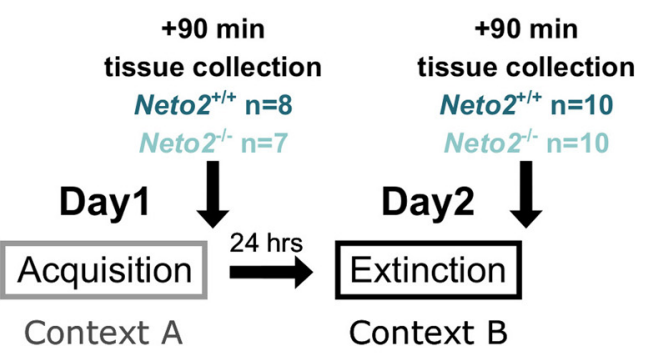

C
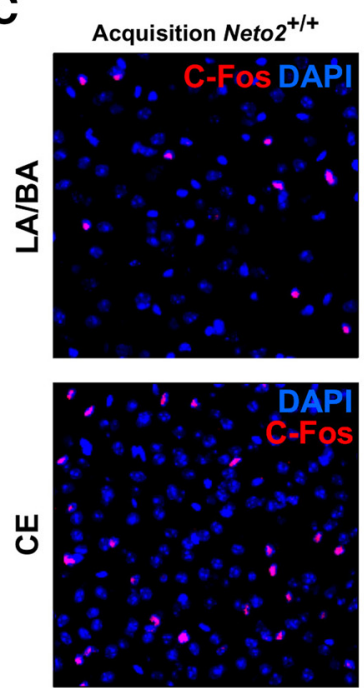

LA/BA

E

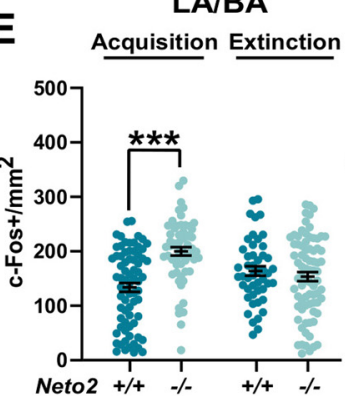

Acquisition $\mathrm{Neto}^{-/-}$
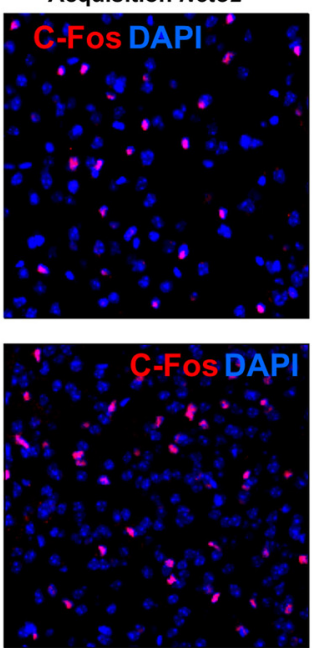

CE

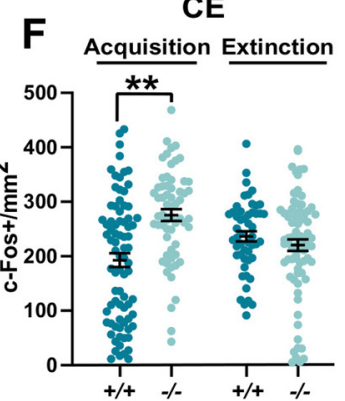

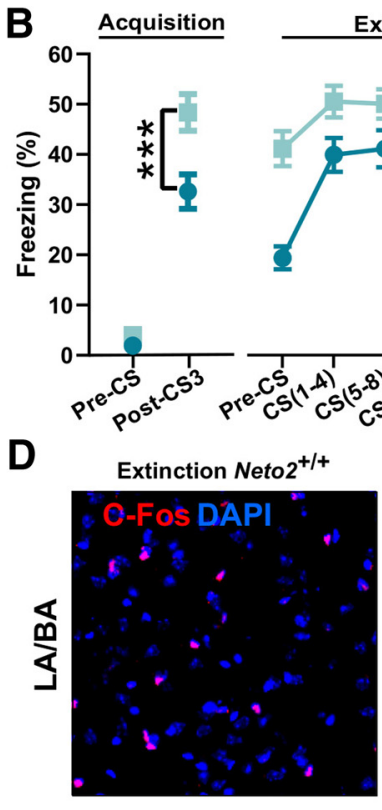

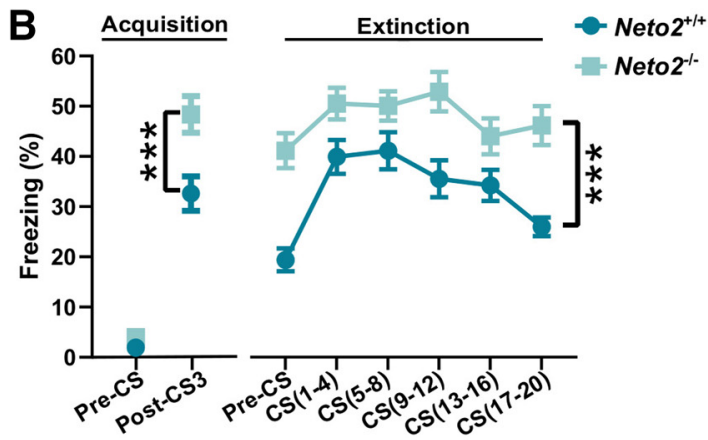

Neto2-1-

D

Extinction $\mathrm{Neto}^{-/-}$
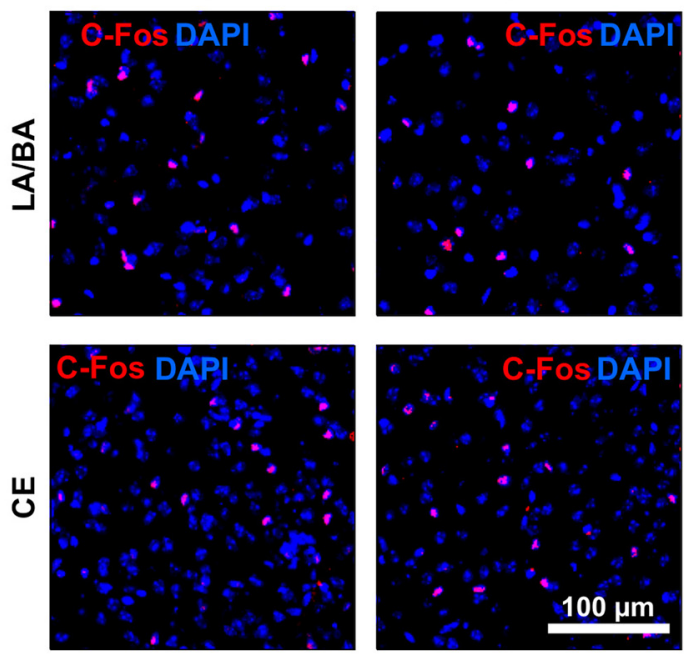

LA/BA

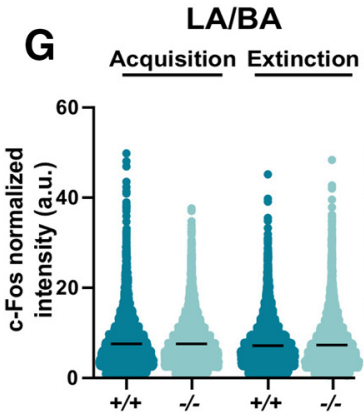

CE

H Acquisition Extinction

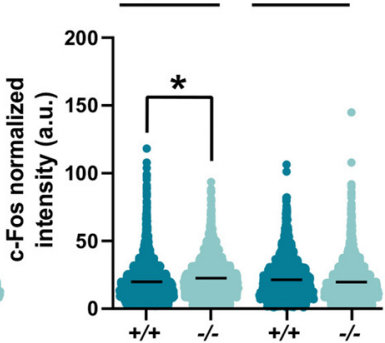

Figure 6. Enhanced fear-induced c-Fos activation in Neto2 ${ }^{-1-}$ amygdala. A, Cued fear conditioning and sample collection schedule. $\boldsymbol{B}$, Freezing percentage of adult $\mathrm{Neto}^{-/-}$and $\mathrm{Neto}^{+/+}$mice during acquisition and within-session extinction of cued fear conditioning (WT $n=42, \mathrm{KO} n=39$ ). Neto $2^{-/-}$mice froze significantly more than $\mathrm{Neto} 2^{+/+}$mice already after the third US-CS pairing (Post-CS3), and they were unable to extinguish the fear memory measured the following day after 20 CS presentations. We collected brain tissue from a subset of these mice $90 \mathrm{~min}$ after the end of fear acquisition or extinction and performed c-Fos staining (acquisition: WT $n=9, \mathrm{KO} n=8$ and extinction: WT $n=10, \mathrm{KO} n=10$ ). Close-up representative images of c-Fos staining in the amygdala of Neto2 $2^{+/+}$and $\mathrm{Neto}^{-/-}$mice after $(\boldsymbol{C})$ fear acquisition or $(\boldsymbol{D})$ extinction. Quantification of CFos ${ }^{+}$cells per $\mathrm{mm}^{2}\left(\mathrm{c}-\mathrm{Fos}^{+} / \mathrm{mm}^{2}\right)$ in (E) LA/BA (analyzed images: acquisition WT $n=73, \mathrm{KO} n=59$; extinction WT $n=48, \mathrm{KO}$ $n=78$ ) and $(\boldsymbol{F})$ CE (analyzed images: acquisition WT $n=80, \mathrm{KO} n=61$; extinction WT $n=51, \mathrm{KO} n=78$ ). Mean intensity of CFos $^{+}$cells in (G) LA/BA (analyzed cells: acquisition WT $n=5453$, KO $n=7146$; extinction WT $n=5052$, KO $n=6954$ ) and $(\boldsymbol{H})$ CE (analyzed cells: acquisition WT $n=2928, \mathrm{KO} n=3317$; extinction WT $n=2461, \mathrm{KO} n=3524$ ). Each dot represents data from one image $(\boldsymbol{E}, \boldsymbol{F})$ or one cell $(\boldsymbol{G}, \boldsymbol{H})$. Mean \pm SEM is shown. Genotype effect calculated using mixed ANOVA (behavior) and GEE analysis (c-Fos); $* p<0.05, * * p<0.01, * * * p<0.001$.

fear memory as shown by the higher intensity of c-Fos staining in the CE. Since the CE is critical for the execution of defensive behaviors, its stronger activation may underlie the higher freezing levels observed in mice lacking NETO2.

\section{Discussion}

In this study, we examined PV interneuron network maturity of the amygdala as a potential mediator of higher fear expression and impaired extinction observed in $\mathrm{Neto}^{-}{ }^{-}$mice. We found that adult, but not juvenile, 
Neto $2^{-1-}$ mice had less $\mathrm{PV}^{+} \mathrm{PNN}^{+}$cells relative to the total population of $\mathrm{PNN}^{+}$cells and lower PV staining intensity, suggesting immaturity and increased plasticity of the $N e t o 2^{-1-}$ amygdala. These findings were associated with a decrease in mIPSC frequency in BA neurons. In addition, we found an increase in mEPSC amplitude and frequency in the BA cells and higher spine density of thin BA dendrites in $\mathrm{Neto}^{-/-}$adult mice, indicating stronger glutamatergic synapses in the absence of NETO2. We also found a larger number of ${\mathrm{C}-\mathrm{Fos}^{+}}^{+}$cells in $\mathrm{Neto}^{-1-}$ mice undergoing associative fear learning, suggesting stronger neuronal recruitment associated with fear acquisition.

We observed that the fraction of the $\mathrm{PV}^{+} \mathrm{PNN}^{+}$double positive cells relative to the total population of $\mathrm{PNN}^{+}$cells was significantly lower in adult, but not juvenile, Neto $2^{-/-}$ compared with $\mathrm{Neto} 2^{+/+}$mice. Chronic fluoxetine treatment, which re-opens critical period-like plasticity in adult mouse brain, causes similar reduction in the fraction of the $\mathrm{PV}^{+} \mathrm{PNN}^{+}$cells relative to the total population of $\mathrm{PNN}^{+}$cells (Karpova et al., 2011). Thus, our finding indicates that the PV interneurons in the adult Neto2 ${ }^{-/-}$ amygdala remain in an immature state. We did not detect genotype differences in the numbers of $\mathrm{PV}^{+}$or $\mathrm{PNN}^{+}$single positive cells. The reliability of immunohistochemical analyses relies on the quality of the used antibodies and how quantitatively they are able to detect the correct antigen. For this reason, we may have missed cells that express very low levels of PV. Despite these challenges, also the PV staining intensity has been used as a molecular plasticity marker, with low PV staining intensity correlating with high levels of plasticity, and the staining intensity increasing with age (Donato et al., 2013, 2015; Umemori et al., 2018). PV intensity levels have also been associated with significant behavioral changes, as shown for environmental enrichment (shift toward low PV intensity) and fear conditioning (shift toward high PV intensity) in the mouse hippocampus (Donato et al., 2013). Inspired by these earlier studies using the same antibody as we used, we measured PV staining intensity in the amygdala. As expected, PV intensity was lower in juvenile than adult WT mice. At P23, PV intensities were similar in Neto $2^{-1-}$ and $\mathrm{Neto}^{+/+}$mice. However, adult Neto2 $2^{-/-}$mice had significantly lower PV intensity than Neto $2^{+/+}$mice, indicating that the maturation of the amygdala PV inhibitory network is perturbed between juvenile and adult ages in the absence of NETO2.

In support of perturbed GABAergic inhibition, mIPSC frequency in BA neurons was significantly lower in Neto $2^{-/-}$as compared with Neto $2^{+/+}$mice. However, this change was mainly because of loss of GABAergic events with a slow rise-time, that are expected to originate from synapses innervating distal dendrites. Since PV interneurons predominantly innervate perisomatic region of the principal neurons (Veres et al., 2017), this result suggests that the absence of NETO2 influences not only PV interneurons but also other subtypes of GABAergic neurons in the amygdala. In the hippocampus, presynaptic KARs regulate GABA release from cholecystokinin (CCK)-positive interneurons depending on the presence of NETO2 (Wyeth et al., 2017), and a comparable mechanism could contribute to the observed decrease in
GABAergic transmission in the BA of $\mathrm{Neto}^{-1-}$ mice. The lack of apparent changes in the frequency of fast, expectedly PV neuron dependent mIPSCs is not necessarily in contrast with the histologic results indicating low intensity of PV immunostaining in the amygdala of $\mathrm{Neto}^{-/-}$mice. $\mathrm{PV}$ is a presynaptic calcium binding protein that regulates neurotransmitter release, and in the absence of endogenous PV, asynchronous GABA release is enhanced (Manseau et al., 2010; Veres et al., 2017). Therefore, increased release because of low PV content might compensate for any effect of reduced GABAergic innervation from $P V$ interneurons, resulting in overall change in the mean mIPSC frequency. In the amygdala, PV interneurons gate plasticity of LA/BA principal neurons and they are crucial for fear memory acquisition during associative fear learning (Wolff et al., 2014). Therefore, an immature and more plastic PV inhibitory network in the amygdala, like in the absence of NETO2, could lead to imbalanced inhibition of amygdala principal neurons during fear learning and consequently result in higher fear expression.

In addition, we found stronger glutamatergic synapses in the BA in the absence of NETO2. Adult Neto2 ${ }^{-1-}$ mice had higher amplitude and frequency of mEPSCs in the BA compared with $\mathrm{Neto} 2^{+/+}$mice. In line with this finding, spine density of thin, but not the thick, dendrites was higher in the BA of $\mathrm{Neto} 2^{-/-}$compared with $\mathrm{Neto} 2^{+/+}$ mice. Morphologically, neurons from the amygdala are variable in shape and have numerous expansions and projections (McDonald, 1982; Pitkänen et al., 2003), but it is not known whether the diameter of the dendrite is related to their maturity. Whether the cells with thick and thin dendrites represent different classes of neurons with different functions remain to be determined. The increase in the strength of glutamatergic connectivity did not significantly affect the basal excitation-inhibition balance (i.e., sEPSC and SIPSC frequency) of the BA network in vitro, possibly because chronic changes in network excitability are efficiently compensated for by various homeostatic mechanisms (Davis, 2013). However, these results do not exclude the possibility that NETO2 deficiency affects recruitment of interneurons during network activity in vivo, which would affect excitation-inhibition balance in the amygdala in response to sensory activity and during behavioral tasks. Consistent with this idea, we did find significantly higher abundance of ${\mathrm{c}-\mathrm{Fos}^{+}}^{+}$cells, a widely used marker for neuronal activation (Chung, 2015), in both LA/BA and CE after fear acquisition in Neto2 ${ }^{-/-}$ compared with $\mathrm{Neto} 2^{+/+}$mice, indicative of higher excitability of the amygdala during a behavioral task. In the BA, the number of ${\mathrm{c}-F o s^{+}}^{+}$cells positively correlates with fear expression of conditioned fear during memory retrieval (Reijmers et al., 2007). It is therefore possible that the increased number of ${\mathrm{C}-\mathrm{Fos}^{+}}^{+}$cells in the Neto2 ${ }^{-1-}$ mice after fear acquisition may be related to stronger associative learning, which is consistent with their higher fear expression phenotype. Thus, NETO2 may facilitate fear acquisition and thereby influence expression of conditioned fear.

Although fear extinction was delayed in the Neto2 $2^{-1-}$ mice, we observed no differences in the number of 
c-Fos $^{+}$cells between genotypes after fear extinction. Fear acquisition and extinction depend on different neuronal populations within the mPFC-amygdala-vHpc network (Herry et al., 2008; Senn et al., 2014). BA principal neurons are central for fear learning and extinction. During fear learning, fear neurons of the $\mathrm{BA}$ receive input from the $\mathrm{vHpc}$ and project to the mPFC, while reciprocal connection between BA extinction neurons and mPFC are necessary for fear extinction (Herry et al., 2008). Especially the IL subregion of the mPFC is required for fear extinction (Cho et al., 2013; Bloodgood et al., 2018). Because of the differential recruitment of these connections during fear learning and extinction, the delayed fear extinction of Neto $2^{-1-}$ mice may originate from deficient neuronal recruitment and/or activity of the MPFC neuronal population that projects to the amygdala rather than from a defect in the amygdala microcircuitry. This is in line with neuroimaging studies of PTSD patients, in which loss of inhibitory control resulting from mPFC hypoactivation, has been suggested to cause hyperactivation of the amygdala and hippocampal atrophy (Shin et al., 2006; Kamiya and Abe, 2020).

Our study has several limitations, and it left open questions to be addressed in future work. Although our results of the immaturity and hyperactivity of the amygdala in the absence of NETO2 are consistent with the higher fear expression and extinction deficit of $\mathrm{Neto}^{-/-}$mice, we have not been able to establish causal links between the main individual findings (i.e., the immature PV network, stronger glutamatergic synapses associated with increased spine density, and increased neuronal activation on fear acquisition) in this article. Neto2 is widely expressed in the fear-associated brain regions, both in the excitatory and inhibitory neurons (Mennesson et al., 2019). Within the developing hippocampus, Neto2 is expressed in $\mathrm{PV}^{+}$, $\mathrm{SOM}^{+}$, and $\mathrm{CCK} /$ cannabinoid receptor $1\left(\mathrm{CCK} / \mathrm{CB} 1^{+}\right)^{-}$ expressing interneurons together with GluK1, GluK2, and GluK5 subunits of KAR (Wyeth et al., 2017). This wide expression pattern makes it challenging to establish causal associations. Very little is known about cell-type-specific functions of NETO2. In the hippocampus, it promotes tonic presynaptic KAR activation and increases inhibition mediated by the CCK/CB1 ${ }^{+}$neurons (Wyeth et al., 2017). In addition to KARs, NETO2 interacts with KCC2 and together with GluK2 increases the total KCC2 abundance (Pressey et al., 2017). Given the wide expression pattern and multiple possible interaction partners, cell-type specific molecular and electrophysiological approaches would be helpful in determining the mechanisms underlying the fear phenotypes of the Neto $2^{-/-}$mice. We used a total $\mathrm{KO}$ model of Neto2, which did not allow us to investigate, for example, whether the morphologic changes of the dendritic spines derive from presynaptic and/or postsynaptic actions of NETO2. Finally, our data suggest that in addition to the amygdala PV network, NETO2 influences also other GABAergic neurons, and these mechanisms remain to be determined.

In conclusion, we established that the higher fear expression and delayed extinction phenotype observed in adult $\mathrm{Neto}^{-/-}$mice is associated with immature features of $\mathrm{PV}$ interneurons and stronger glutamatergic synapses within the amygdala. Moreover, neuronal activation of the amygdala was increased after fear learning in the absence of NETO2, possibly leading to stronger associative memories, consistent with higher fear expression after acquisition. However, the higher amygdala excitability derives from other than PV inputs to the pyramidal cells, and the mechanistic basis of this finding remains to be studied in the future. Higher fear expression has been associated with higher conditionability, which together with slower extinction, is a phenotype observed in human PTSD (Orr et al., 2000; Blechert et al., 2007; Wegerer et al., 2013). Therefore, Neto $2^{-/-}$mice may be used as a model for PTSD risk. This model could be especially useful for studying the role of maturity and plasticity of the amygdala in fear-related disorders.

\section{References}

Beurdeley M, Spatazza J, Lee HH, Sugiyama S, Bernard C, Di Nardo AA, Hensch TK, Prochiantz A (2012) Otx2 binding to perineuronal nets persistently regulates plasticity in the mature visual cortex. $J$ Neurosci 32:9429-9437.

Blechert J, Michael T, Vriends N, Margraf J, Wilhelm FH (2007) Fear conditioning in posttraumatic stress disorder: evidence for delayed extinction of autonomic, experiential, and behavioural responses. Behav Res Ther 45:2019-2033.

Bloodgood DW, Sugam JA, Holmes A, Kash TL (2018) Fear extinction requires infralimbic cortex projections to the basolateral amygdala. Transl Psychiatry 8:60.

Carstens KE, Phillips ML, Pozzo-Miller L, Weinberg RJ, Dudek SM (2016) Perineuronal nets suppress plasticity of excitatory synapses on CA2 pyramidal neurons. J Neurosci 36:6312-6320.

Cho JH, Bayazitov IT, Meloni EG, Myers KM, Carlezon WA Jr, Zakharenko SS, Bolshakov VY (2011) Coactivation of thalamic and cortical pathways induces input timing-dependent plasticity in amygdala. Nat Neurosci 15:113-122.

Cho JH, Deisseroth K, Bolshakov VY (2013) Synaptic encoding of fear extinction in mPFC-amygdala circuits. Neuron 80:1491-1507.

Chung $L$ (2015) A brief introduction to the transduction of neural activity into Fos signal. Dev Reprod 19:61-67.

Davis GW (2013) Homeostatic signaling and the stabilization of neural function. Neuron 80:718-728.

Donato F, Rompani SB, Caroni P (2013) Parvalbumin-expressing basket-cell network plasticity induced by experience regulates adult learning. Nature 504:272-276.

Donato F, Chowdhury A, Lahr M, Caroni P (2015) Early- and lateborn parvalbumin basket cell subpopulations exhibiting distinct regulation and roles in learning. Neuron 85:770-786.

Ehrlich I, Humeau Y, Grenier F, Ciocchi S, Herry C, Lüthi A (2009) Amygdala inhibitory circuits and the control of fear memory. Neuron 62:757-771.

Fitzgerald PJ, Pinard CR, Camp MC, Feyder M, Sah A, Bergstrom HC, Graybeal C, Liu Y, Schlüter OM, Grant SG, Singewald N, Xu W, Holmes A (2015) Durable fear memories require PSD-95. Mol Psychiatry 20:901-912.

Gogolla N, Caroni P, Lüthi A, Herry C (2009) Perineuronal nets protect fear memories from erasure. Science 325:1258-1261.

Guirado R, Perez-Rando M, Sanchez-Matarredona D, Castrén E, Nacher $J$ (2014) Chronic fluoxetine treatment alters the structure, connectivity and plasticity of cortical interneurons. Int $\mathrm{J}$ Neuropsychopharmacol 17:1635-1646.

Gunduz-Cinar O, Brockway E, Lederle L, Wilcox T, Halladay LR, Ding Y, Oh H, Busch EF, Kaugars K, Flynn S, Limoges A, Bukalo O, MacPherson KP, Masneuf S, Pinard C, Sibille E, Chesler EJ, Holmes A (2019) Identification of a novel gene regulating amygdala-mediated fear extinction. Mol Psychiatry 24:601-612. 
Hanley JA, Negassa A, Edwardes MD, Forrester JE (2003) Statistical analysis of correlated data using generalized estimating equations: an orientation. Am J Epidemiol 157:364-375.

Herry C, Johansen JP (2014) Encoding of fear learning and memory in distributed neuronal circuits. Nat Neurosci 17:1644-1654.

Herry C, Ciocchi S, Senn V, Demmou L, Müller C, Lüthi A (2008) Switching on and off fear by distinct neuronal circuits. Nature 454:600-606.

Herry C, Ferraguti F, Singewald N, Letzkus JJ, Ehrlich I, Lüthi A (2010) Neuronal circuits of fear extinction. Eur J Neurosci 31:599612.

Ivakine EA, Acton BA, Mahadevan V, Ormond J, Tang M, Pressey JC, Huang MY, Ng D, Delpire E, Salter MW, Woodin MA, Mclnnes RR (2013) Neto2 is a KCC2 interacting protein required for neuronal $\mathrm{Cl}$ - regulation in hippocampal neurons. Proc Natl Acad Sci USA 110:3561-3566.

Johansen JP, Hamanaka H, Monfils MH, Behnia R, Deisseroth K, Blair HT, LeDoux JE (2010) Optical activation of lateral amygdala pyramidal cells instructs associative fear learning. Proc Natl Acad Sci USA 107:12692-12697.

Johansen JP, Cain CK, Ostroff LE, LeDoux JE (2011) Molecular mechanisms of fear learning and memory. Cell 147:509-524.

Kamiya K, Abe O (2020) Imaging of posttraumatic stress disorder. Neuroimaging Clin N Am 30:115-123.

Karpova NN, Pickenhagen A, Lindholm J, Tiraboschi E, Kulesskaya $\mathrm{N}$, Agústsdóttir A, Antila H, Popova D, Akamine Y, Bahi A, Sullivan R, Hen R, Drew LJ, Castrén E (2011) Fear erasure in mice requires synergy between antidepressant drugs and extinction training. Science 334:1731-1734.

Ko S, Zhao MG, Toyoda H, Qu CS, Zhuo M (2005) Altered behavioral responses to noxious stimuli and fear in glutamate receptor 5 (GluR5)- or GluR6-deficient mice. J Neurosci 25:977-984.

Laine MA, Trontti K, Misiewicz Z, Sokolowska E, Kulesskaya N, Heikkinen A, Saarnio S, Balcells I, Ameslon P, Greco D, Mattila P, Ellonen P, Paulin L, Auvinen P, Jokitalo E, Hovatta I (2018) Genetic control of myelin plasticity after chronic psychosocial stress. eNeuro 5:ENEURO.0166-18.2018.

Li H, Chen A, Xing G, Wei ML, Rogawski MA (2001) Kainate receptormediated heterosynaptic facilitation in the amygdala. Nat Neurosci 4:612-620.

Lorenzo Bozzelli P, Alaiyed S, Kim E, Villapol S, Conant K (2018) Proteolytic remodeling of perineuronal nets: effects on synaptic plasticity and neuronal population dynamics. Neural Plast 2018:5735789.

Lucas EK, Jegarl AM, Morishita H, Clem RL (2016) Multimodal and site-specific plasticity of amygdala parvalbumin interneurons after fear learning. Neuron 91:629-643.

McDonald AJ (1982) Neurons of the lateral and basolateral amygdaIoid nuclei: a Golgi study in the rat. J Comp Neurol 212:293-312.

Mennesson M, Rydgren E, Lipina T, Sokolowska E, Kulesskaya N, Morello F, Ivakine E, Voikar V, Risbrough V, Partanen J, Hovatta I (2019) Kainate receptor auxiliary subunit NETO2 is required for normal fear expression and extinction. Neuropsychopharmacol 44:1855-1866.

Morikawa S, Ikegaya Y, Narita M, Tamura H (2017) Activation of perineuronal net-expressing excitatory neurons during associative memory encoding and retrieval. Sci Rep 7:46024.

Nowicka D, Soulsby S, Skangiel-Kramska J, Glazewski S (2009) Parvalbumin-containing neurons, perineuronal nets and experience-dependent plasticity in murine barrel cortex. Eur J Neurosci 30:2053-2063.

Ohira K, Takeuchi R, Iwanaga T, Miyakawa T (2013) Chronic fluoxetine treatment reduces parvalbumin expression and perineuronal nets in gamma-aminobutyric acidergic interneurons of the frontal cortex in adult mice. Mol Brain 6:43.

Orav E, Atanasova T, Shintyapina A, Kesaf S, Kokko M, Partanen J, Taira T, Lauri SE (2017) NETO1 guides development of glutamatergic connectivity in the hippocampus by regulating axonal kainate receptors. eNeuro 4:ENEURO.0048-17.2017.
Orr SP, Metzger LJ, Lasko NB, Macklin ML, Peri T, Pitman RK (2000) De novo conditioning in trauma-exposed individuals with and without posttraumatic stress disorder. J Abnorm Psychol 109:290298.

Pattwell SS, Bath KG, Casey BJ, Ninan I, Lee FS (2011) Selective early-acquired fear memories undergo temporary suppression during adolescence. Proc Natl Acad Sci USA 108:1182-1187.

Pattwell SS, Duhoux S, Hartley CA, Johnson DC, Jing D, Elliott MD, Ruberry EJ, Powers A, Mehta N, Yang RR, Soliman F, Glatt CE, Casey BJ, Ninan I, Lee FS (2012) Altered fear learning across development in both mouse and human. Proc Natl Acad Sci USA 109:16318-16323.

Pitkänen A, Savander M, Nurminen N, Ylinen A (2003) Intrinsic synaptic circuitry of the amygdala. Ann NY Acad Sci 985:34-49.

Pressey JC, Mahadevan V, Khademullah CS, Dargaei Z, Chevrier J, Ye W, Huang M, Chauhan AK, Meas SJ, Uvarov P, Airaksinen MS, Woodin MA (2017) A kainate receptor subunit promotes the recycling of the neuron-specific $\mathrm{K}(+)-\mathrm{Cl}(-)$ co-transporter KCC2 in hippocampal neurons. J Biol Chem 292:6190-6201.

Reijmers LG, Perkins BL, Matsuo N, Mayford M (2007) Localization of a stable neural correlate of associative memory. Science 317:1230-1233.

Ruediger S, Vittori C, Bednarek E, Genoud C, Strata P, Sacchetti $B$, Caroni P (2011) Learning-related feedforward inhibitory connectivity growth required for memory precision. Nature 473:514518.

Senn V, Wolff SB, Herry C, Grenier F, Ehrlich I, Gründemann J, Fadok JP, Müller C, Letzkus JJ, Lüthi A (2014) Long-range connectivity defines behavioral specificity of amygdala neurons. Neuron 81:428-437.

Shin LM, Rauch SL, Pitman RK (2006) Amygdala, medial prefrontal cortex, and hippocampal function in PTSD. Ann NY Acad Sci 1071:67-79.

Shin RM, Tully K, Li Y, Cho JH, Higuchi M, Suhara T, Bolshakov VY (2010) Hierarchical order of coexisting pre- and postsynaptic forms of long-term potentiation at synapses in amygdala. Proc Natl Acad Sci USA 107:19073-19078.

Tang M, Pelkey KA, Ng D, Ivakine E, McBain CJ, Salter MW, Mclnnes RR (2011) Neto1 is an auxiliary subunit of native synaptic kainate receptors. J Neurosci 31:10009-10018.

Tovote P, Fadok JP, Lüthi A (2015) Neuronal circuits for fear and anxiety. Nat Rev Neurosci 16:317-331.

Umemori J, Winkel F, Castrén E, Karpova NN (2015) Distinct effects of perinatal exposure to fluoxetine or methylmercury on parvalbumin and perineuronal nets, the markers of critical periods in brain development. Int J Dev Neurosci 44:55-64.

Umemori J, Winkel F, Didio G, Llach Pou M, Castrén E (2018) iPlasticity: induced juvenile-like plasticity in the adult brain as a mechanism of antidepressants. Psychiatry Clin Neurosci 72:633653.

Manseau F, Marinelli S, Méndez P, Schwaller B, Prince DA, Huguenard JR, Bacci A (2010) Desynchronization of neocortical networks by asynchronous release of GABA at autaptic and synaptic contacts from fast-spiking interneurons. PLoS Biol 8: e1000492.

Veres JM, Nagy GA, Hájos N (2017) Perisomatic GABAergic synapses of basket cells effectively control principal neuron activity in amygdala networks. Elife 6:e20721.

Wang D, Fawcett $J$ (2012) The perineuronal net and the control of CNS plasticity. Cell Tissue Res 349:147-160.

Wegerer M, Blechert J, Kerschbaum H, Wilhelm FH (2013) Relationship between fear conditionability and aversive memories: evidence from a novel conditioned-intrusion paradigm. PLoS One 8:e79025.

Wolff SB, Gründemann J, Tovote P, Krabbe S, Jacobson GA, Müller C, Herry C, Ehrlich I, Friedrich RW, Letzkus JJ, Lüthi A (2014) Amygdala interneuron subtypes control fear learning through disinhibition. Nature 509:453-458. 
Wyeth MS, Pelkey KA, Yuan X, Vargish G, Johnston AD, Hunt S, Fang C, Abebe D, Mahadevan V, Fisahn A, Salter MW, Mclnnes RR, Chittajallu R, McBain CJ (2017) Neto auxiliary subunits regulate interneuron somatodendritic and presynaptic kainate receptors to control network inhibition. Cell Rep 20:2156-2168.
Zhang W, St-Gelais F, Grabner CP, Trinidad JC, Sumioka A, Morimoto-Tomita M, Kim KS, Straub C, Burlingame AL, Howe JR, Tomita S (2009) A transmembrane accessory subunit that modulates kainate-type glutamate receptors. Neuron 61:385396. 